This document is confidential and is proprietary to the American Chemical Society and its authors. Do not copy or disclose without written permission. If you have received this item in error, notify the sender and delete all copies.

\title{
Spin crossover behaviour in a homologous series of iron(II) complexes based on functionalized-bipyridyl ligands
}

\begin{tabular}{|r|l|}
\hline Journal: & Inorganic Chemistry \\
\hline Manuscript ID & ic-2018-00850p.R1 \\
\hline Manuscript Type: & Article \\
\hline Date Submitted by the Author: & n/a \\
\hline Complete List of Authors: & $\begin{array}{l}\text { Xue, Shufang; Universite catholique de Louvain, Institute of Condensed } \\
\text { Matter and Nanosciences } \\
\text { Guo, Yunnan; Universite catholique de Louvain, Institute of Condensed } \\
\text { Matter and Nanosciences } \\
\text { Rotaru, Aurelian; Stefan cel Mare University of Suceava, Faculty of } \\
\text { Electrical Engineering and Computer Science } \\
\text { Müller-Bunz, Helge; UCD, School of Chemistry and Chemical Biology } \\
\text { Morgan, Grace; University College Dublin, School of Chemistry \& Chemical } \\
\text { Biology } \\
\text { Trzop, Elzbieta; Universite de Rennes 1, Institut de Pysique de Rennes - } \\
\text { Physics } \\
\text { Collet, Eric; Institut de Physique de Rennes, Physics } \\
\text { Olah, Julianna; Budapest University of Technology and Economics } \\
\text { Garcia, Yann; Université Catholique de Louvain, Institute of Condensed } \\
\text { Matter and Nanosciences }\end{array}$ \\
\hline
\end{tabular}




\section{Spin crossover behaviour in a homologous series of iron(II) complexes based on functionalized-bipyridyl ligands}

Shufang Xue,$^{\dagger}$ Yunnan Guo, ${ }^{\dagger}$ Aurelian Rotaru, ${ }^{\ddagger}$ Helge Müller-Bunz, ${ }^{\S}$ Grace G. Morgan, ${ }^{\S}$ Elzbieta Trzop, "Eric Collet", Julianna Oláh ${ }^{\square}$ and Yann Garcia ${ }^{\dagger,{ }^{*}}$

${ }^{\dagger}$ Institute of Condensed Matter and Nanosciences, Molecules, Solids and Reactivity (IMCN/MOST), Université catholique de Louvain, Place L. Pasteur 1, 1348 Louvainla-Neuve, Belgium

${ }^{\ddagger}$ Department of Electrical Engineering and Computer Science \& MANSiD Research Center, "Stefan cel Mare" University, University Street, 13, Suceava 720229 Romania

§School of Chemistry, University College Dublin, Belfield, Dublin 4, Ireland

"Univ Rennes 1, CNRS, Institut de Physique de Rennes, UMR 6251, UBL,

35042 Rennes, France

Department of Inorganic and Analytical Chemistry, Budapest University of Technology and Economics, H-1111 Szent Gellért tér 4. Budapest, Hungary 


\begin{abstract}
A series of bulky substituted bipyridine-related iron(II) complexes $\left[\mathrm{Fe}\left(\mathrm{H}_{2} \mathrm{Bpz}_{2}\right)_{2}(\mathrm{~L})\right]$ ( $\mathrm{pz}=$ pyrazolyl) were prepared, where $\mathrm{L}=5,5$ '-dimethyl-2,2'bipyridine (bipy- $\mathrm{CH}_{3}, \mathbf{1}$ ), $\mathrm{L}=$ dimethyl-2,2'-bipyridyl-5,5'-dicarboxylate (MeObpydc, 2), $\mathrm{L}=$ diethyl-2,2'-bipyridyl-5,5'-dicarboxylate (EtObpydc, 3), L = diisopropyl-2,2'bipyridine-5,5'-dicarboxylate (i-PrObpydc, 4). The crystal structures of five new iron(II) complexes were determined by X-ray diffraction: the one of 1, 3 and 4 as well as two modifications of 3 (3B) and 4 (4B). Complexes 1 and $3 B$ display incomplete spin crossover (SCO) behavior due to a freezing-in effect whereas 3 and 4B undergo gradual and incomplete SCO behaviors. Complexes 2 and $\mathbf{4}$ show a completely gradual and steep SCO, respectively. Such different SCO behaviors can be attributed to electronic substituent effect in bipyridyl ligand conformation and crystalpacking effect. Importantly, the electronic substituent effect of the isopropyl acetate group and $\mathrm{C}-\mathrm{H} \cdots \mathrm{O}$ supramolecular interactions in $\mathbf{4}$ contribute to a highly cooperative behavior, which leads to an abrupt thermally induced spin transition.
\end{abstract}




\section{INTRODUCTION}

Spin crossover (SCO), a spin-switching phenomenon that may exist in $3 d^{4}-3 d^{7}$ transition metal complexes, is regarded as a fascinating field of investigation finding echo in as diverse potential applications such as ultra-high-density memory devices, sensors, molecular electronics and spintronics. ${ }^{1}$ Such outstanding and useful physical property is due to the switching between the low-spin (LS) and high-spin (HS) states in a reversible, detectable and controllable fashion by the action of external stimuli (temperature, pressure, light irradiation and chemical decoration). The switching can be accompanied by drastic changes in the magnetic properties (diamagnetism-paramagnetism), but also with some physical response such as structural, vibrational, dielectric, and optical properties. ${ }^{2}$ Until now, the majority of SCO materials involve spin carriers surrounded by different organic ligands with various morphologies. In order to realize potential applications, the properties referring to an abrupt and complete signal response ${ }^{3}$ with a hysteresis ${ }^{4}$ around room temperature are considered as very important requirements. One efficient approach results from the fine-tuning the ligand field around the metal center as well as the control of supramolecular interactions (crystal packing effects) between switching units, thus justifying the use of crystal engineering concepts. Bipydine (bipy) is considered as a classical representative of imine ligands for SCO systems. ${ }^{5}$ The spin nature of these complexes lies in the high $\sigma$-donor power of the imine function and the empty, low-lying $\pi$ orbitals of the ligand molecules. Therefore an effective strategy to tune the ligand field strength of bipy complexes into the crossover range consists in modifying the $\sigma$-donor or $\pi$-acceptor character. ${ }^{5}$ From the standpoint of organic synthesis, it was thought to substitute the bipy ligand at the $C_{3}, C_{4}, C_{5}$ and $\mathrm{C}_{6}$ positions, to explore the impact of the electronic substituent effect and crystal packing on the SCO properties. Substituents at the $\mathrm{C}_{3},{ }^{6}$ and $\mathrm{C}_{6},{ }^{7}$ positions have a strong influence on the iron spin-state, as well as on steric and electronic grounds. Conversely, provided that the substituents are at positions relatively remote from the donor atoms $\left(\mathrm{C}_{4}\right.$ and $\mathrm{C}_{5}$ ), no significant change occurs in the ligand field strength as well as on the $\left[\mathrm{FeN}_{6}\right]^{2+}$ core. ${ }^{8},{ }^{9}$ One exception is the occurrence of "spin equilibrium" in the $\mathrm{Fe}^{\prime \prime}$ complex of 5,5'-diethylcarboxylate-2,2'-bipyridine. ${ }^{8}$

As the archetype of bipy-related SCO systems, the mononuclear complex $\left[\mathrm{Fe}\left(\mathrm{H}_{2} \mathrm{Bpz}_{2}\right)_{2}(\mathrm{~L})\right](\mathrm{pz}=$ pyrazolyl, $\mathrm{L}=$ bipy $)$ was found to exhibit a thermally induced 
SCO transition at $160 \mathrm{~K},{ }^{10}$ also with pressure ${ }^{11}$ and light irradiation. ${ }^{12}$ Since then, successive efforts have concentrated on the modification of the bipy ligand, involving for instance a diarylethene photoisomerizable unit for ligand driven light induced spin change. ${ }^{13}$ An interdigitated aromatic donor group to allow strong $\pi \cdots \pi$ interactions in the crystal lattice of mononuclear iron(II) complexes was also introduced. ${ }^{14}$ Hydrophilic alkyl tails were also added to improve the spin-transition temperature via nanosphere organization. ${ }^{15} \mathrm{~A}$ strong electron-donating amino group was also recently introduced. ${ }^{16}$ Amazingly, protonation of the amino group in $\left[\mathrm{Fe}\left(\mathrm{H}_{2} \mathrm{Bpz}\right)_{2}\left(\right.\right.$ bipy- $\left.\left.\mathbf{N H}_{2}\right)\right]$ (bipy- $\mathbf{N H}_{\mathbf{2}}=4,4$ '-diamino-2,2'-bipyridine) displays spectacular enhancement of $T_{1 / 2}$ from $160 \mathrm{~K}$ to $297 \mathrm{~K}$, allowing operating SCO around room temperature. ${ }^{16}$ Notwithstanding these representative examples, the investigation of structure-property relationships is at the heart of the SCO field to reach a full control of magnetic properties. Aiming, herein, at shedding light on the SCO influence of bipy substituents, we have designed a series of bulky substituted bipy-ligands at $\mathrm{C}_{5}$ and $\mathrm{C}_{5}$, positions (Scheme 1), and assembled Fe" complexes 1-4. Hopefully, the central skeleton of $\mathrm{FeN}_{6}$ was found similar to the original crystal arrangement around the $\mathrm{Fe}^{\prime \prime}$ center $^{10}$, which allows meaningful comparisons. Due to the electronic substituent effect and crystal-packing effect, the SCO behavior drastically differs from complexes to complexes: $\mathbf{1}$ and 3B displays incomplete SCO behavior, 2 shows a gradual SCO whereas 3 and 4B undergo gradual and incomplete SCO behaviors. Importantly, the combination between electronic substituent effect of the isopropyl acetate group and $\mathrm{C}-\mathrm{H} \cdots \mathrm{O}$ interactions in $\mathbf{4}$ provide relatively high cooperativity, which leads to an abrupt SCO behavior.

Scheme 1. Fe" complexes based on a series of bulky substituted bipy-ligands at $C_{5}$ and $\mathrm{C}_{5}$ positions 


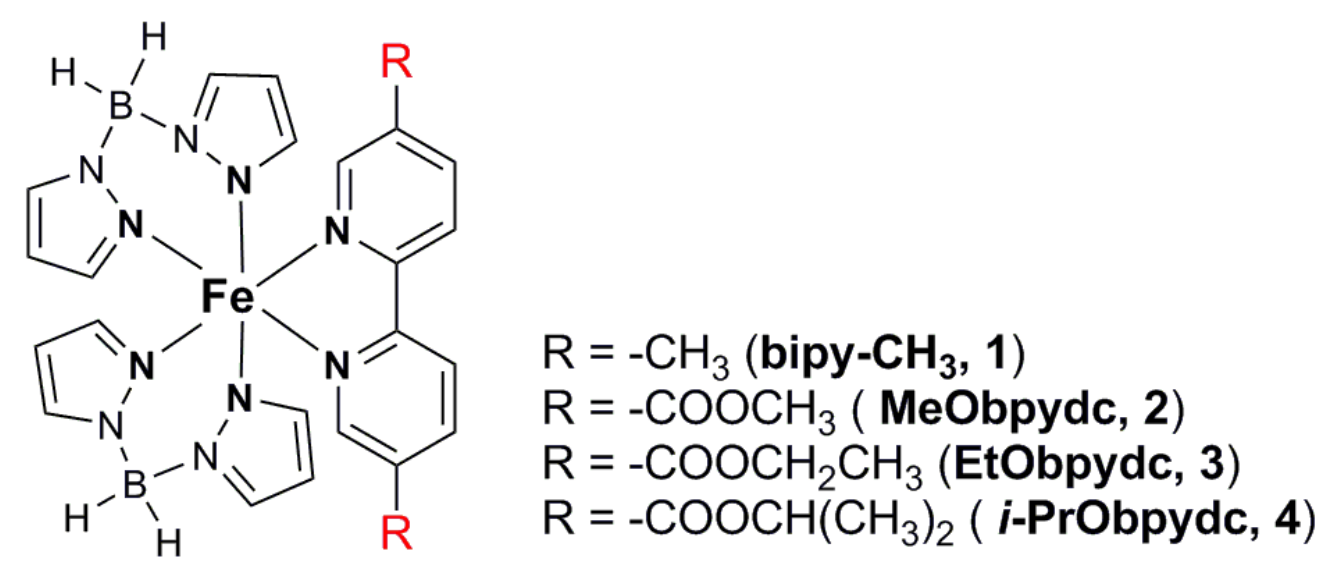

\section{RESULTS}

2.1. Synthesis and General Characterization. The bipy-type ligands (Scheme 1), 2,2'-bipyridine-5,5'-dicarboxylic acid (bpydc), ${ }^{17}$ dimethyl-2,2'-bipyridyl-5,5'dicarboxylate (MeObpydc), ${ }^{18}$ diethyl-2,2'-bipyridyl-5,5'-dicarboxylate (EtObpydc) ${ }^{19}$ and diisopropyl-2,2'-bipyridine-5,5'-dicarboxylate (i-PrObpydc) ${ }^{20}$ were prepared following literature procedures. Powder samples for 1-4 were prepared by similar procedures described in the literature (Scheme 2$).{ }^{10}$

Scheme 2. Synthetic procedure for the bulky substituted bipy ligands (bipy- $\mathbf{C H}_{3}$, MeObpydc, EtObpydc and i-PrObpydc) and the iron (II) complexes (1-4).
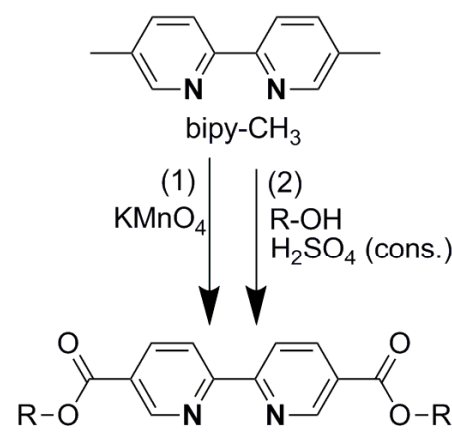

$\mathrm{R}=-\mathrm{CH}_{3}, \mathrm{MeObpydc}$ $\mathrm{R}=-\mathrm{CH}_{2} \mathrm{CH}_{3}$ EtObpydc $\mathrm{R}=-\mathrm{CH}\left(\mathrm{CH}_{3}\right)_{2}, i-\mathrm{PrObpydc}$
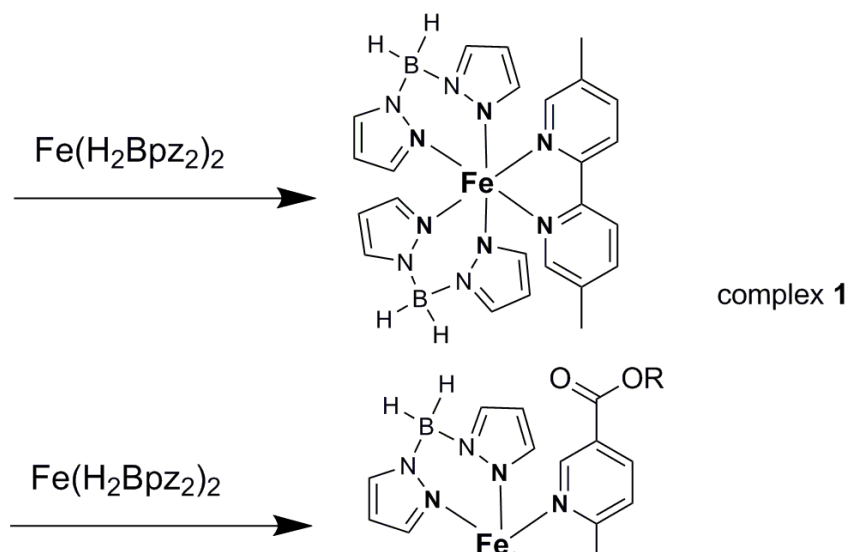

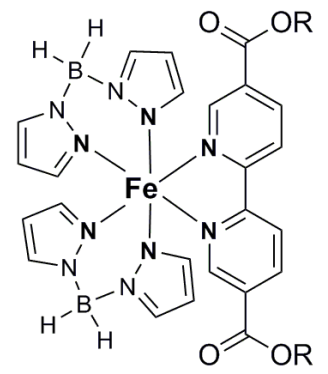

complexes 2-4

Single crystal of 1 was obtained by slow diffusion in $\mathrm{MeOH}$ under $\mathrm{Ar}_{(\mathrm{g})}$, using a single-tube glass vessel. The bipy- $\mathrm{CH}_{3}$ in $\mathrm{CH}_{3} \mathrm{OH}$ was placed on the top a $\mathrm{Fe}\left(\mathrm{H}_{2} \mathrm{Bpz}_{2}\right)_{2}$ methanolic solution. Given to the different solubility, single crystals of 3 and 4 were obtained by slow diffusion in methanol/dichloromethane mixture under 
$\operatorname{Ar}_{(g)}$ using a single-tube glass vessel. The bipyridine dicarboxylate (MeObpydc, EtObpydc or $\boldsymbol{i}$-PrObpydc) in $\mathrm{CH}_{2} \mathrm{Cl}_{2}$ was placed on the bottom of a methanolic solution containing $\mathrm{Fe}\left(\mathrm{H}_{2} \mathrm{Bpz}_{2}\right)_{2}$. Pink-violet single crystals for $\mathbf{1}$ and dark green bulk crystals for $\mathbf{3}$ and $\mathbf{4}$, namely $\mathbf{3 B}$ and $\mathbf{4 B}$ formed after one week. Of particular interest was that needle crystals of $\mathbf{3}$ and $\mathbf{4}$ were observed after one night. Attempts to crystallize 2 failed due to the poor solubility of MeObpydc ligand, yielding systematically to a solid crystalline product despite numerous varied reaction conditions. All these complexes were successfully characterized by elemental analysis, mass spectra analysis (MS), thermogravimetric analysis (TGA), Fouriertransform infrared spectroscopy (FTIR), differential thermal analysis (DSC), singlecrystal X-ray diffraction, magnetic susceptibility measurements and ${ }^{57} \mathrm{Fe}$ Mössbauer spectroscopy. The crystal structures of all the complexes except 2 were determined by single-crystal $\mathrm{X}$-ray diffraction at variable temperatures. Details for the structure solution and refinement are summarized in Table $\mathrm{S} 1$ and selected bond distances and angles are listed in Table S2. Importantly, no lattice solvent molecules were detected neither by crystallography nor by TGA (Figure 1). The thermal stability of complexes 1-4 was found very high, above $500 \mathrm{~K}$ for $\mathbf{1}$ and $\mathbf{4}$, or slightly below for 2 and 3. FTIR analysis revealed that all the complexes have a similar coordination mode irrespective of the bipy-type ligand around the iron(II) centre (Figure S1). 


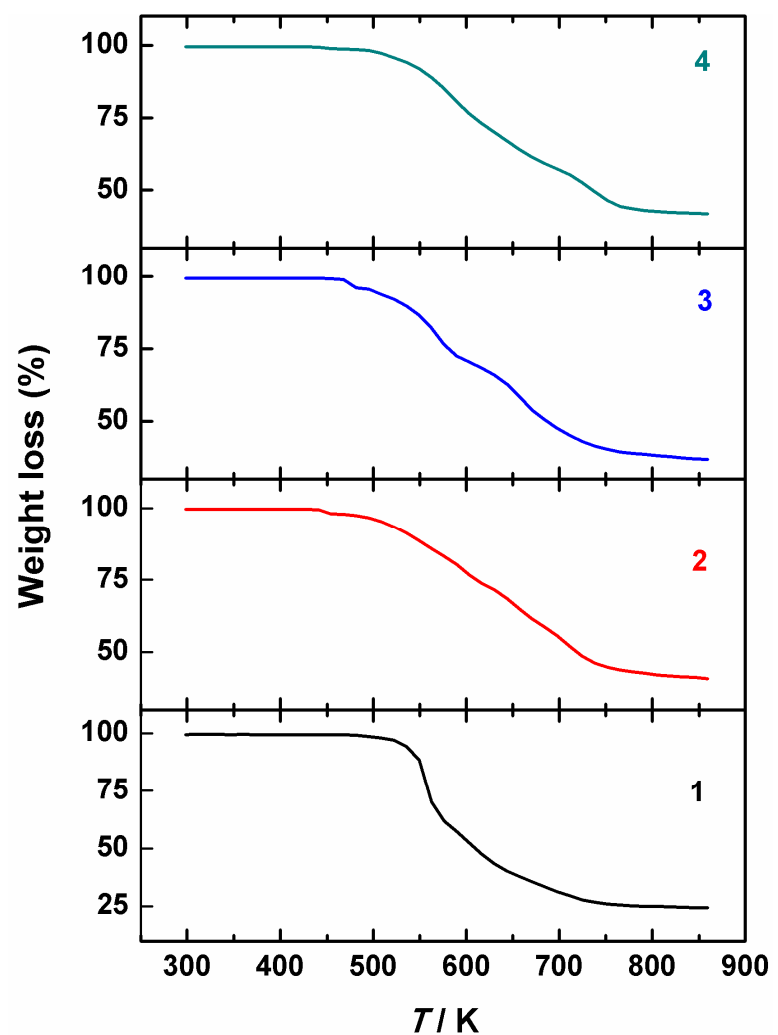

Figure 1. TGA profile for powder samples 1-4 performed under a $\mathrm{N}_{2(\mathrm{~g})}$.

\subsection{X-ray crystallography}

Crystal structure of 1 . Complex 1 crystallizes in the monoclinic $P 2_{1} / c$ space group with the formula $\left[\mathrm{Fe}\left(\mathrm{H}_{2} \mathrm{Bpz}_{2}\right)_{2}\left(\right.\right.$ bipy $\left.\left.-\mathrm{CH}_{3}\right)\right]$. A perspective view of the molecular structure of 1 at $95 \mathrm{~K}$ is represented in Figure 2. The whole molecule consists of one bidentate bipy- $\mathrm{CH}_{3}$ group and two $\left(\mathrm{H}_{2} \mathrm{Bpz}_{2}\right)^{-}$anions coordinated to $\mathrm{Fe}$ "l in cis mode. The Fe- $\mathrm{N}$ bond lengths are in the range of 2.150(2)-2.240(2) $\AA$ which is consistent with HS Fe". The cis angles of the iron(II) coordination sphere range from 74.62(9) to $98.38(9)^{\circ}$, and the octahedral distortion parameter $(\Sigma)$ is found to be $50.7^{\circ}$. Although a $\mathrm{FeN}_{6}$ core is identified, which matches the one of the reference complex $\left[\mathrm{Fe}\left(\mathrm{H}_{2} \mathrm{Bpz}\right)_{2}\right.$ (bipy)] (5), ${ }^{9}$ a comparison of the bond distances in 1 and 5 (Figure S2) shows considerable differences in the ligand field strength, thus leading to different magnetic behaviors (vide infra). The crystal packing also shows some differences with weaker $\pi^{\cdots} \pi$ interactions between the adjacent bipy ligands in 1 than that in 5 (Figure S3). 


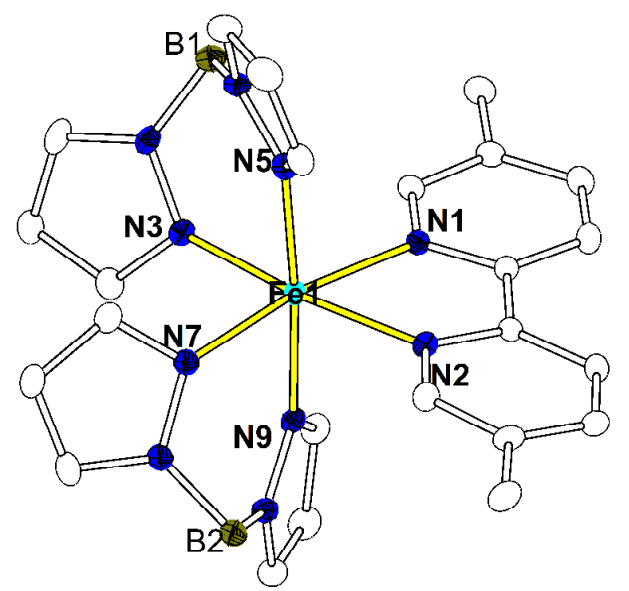

Figure 2. Perspective view of the molecular structure of 1 at $95 \mathrm{~K}$. Displacement ellipsoids are drawn at the $30 \%$ probability level and $\mathrm{H}$ atoms were omitted for the sake of clarity.

Careful inspection of the packing arrangement (Figure S3) reveals a 2D supramolecular structure which is organized via weak $\mathrm{C}-\mathrm{H} \cdots \pi$ intermolecular interactions (C3-H3 $\cdots$ centroid and $\mathrm{C} 11-\mathrm{H} 11 \mathrm{~B} \cdots$ centroid distance: $2.513 \AA$ and 2.828 $\AA$ ) from the bipy- $\mathrm{CH}_{3}$ ligand to a pyrazolyl moiety. Attempts to collect data at $20 \mathrm{~K}$ after detecting a spin state crossover below $90 \mathrm{~K}$ from magnetic measurements (see Figure 12), reveals the Fe-N bond length is still larger than $2.1 \AA$ (Table S2). In this case, $\mathrm{X}$-ray crystallography is limited for spin detection given the low amount of spin carriers involved in the SCO process (ca. $10 \%$ as found by ${ }^{57} \mathrm{Fe}$ Mössbauer spectroscopy, vide infra). The HS state could also result from flash cooling of the crystals from room temperature by our He cryostream at $20 \mathrm{~K}$ which may trap the HS state, as observed on another example by $\mathrm{X}$-ray diffraction. ${ }^{21}$

Crystal structures of $\mathbf{3}$ and $\mathbf{4}$. In order to avoid the occurrence of transesterification (vide infra), crystal growth was carried out overnight with the corresponding ligandcontaining dichloromethane solution into a methanolic solution of $\mathrm{Fe}\left(\mathrm{H}_{2} \mathrm{Bpz}\right)_{2}$ leading to X-ray quality crystals of $\mathbf{3}$ and $\mathbf{4}$ of $\left[\mathrm{Fe}\left(\mathrm{H}_{2} \mathrm{Bpz}_{2}\right)_{2}(\right.$ EtObpydc $\left.)\right]$ and $\left[\mathrm{Fe}\left(\mathrm{H}_{2} \mathrm{Bpz}\right)_{2}(i\right.$-PrObpydc)], respectively (Figures 3 and 4$)$. 


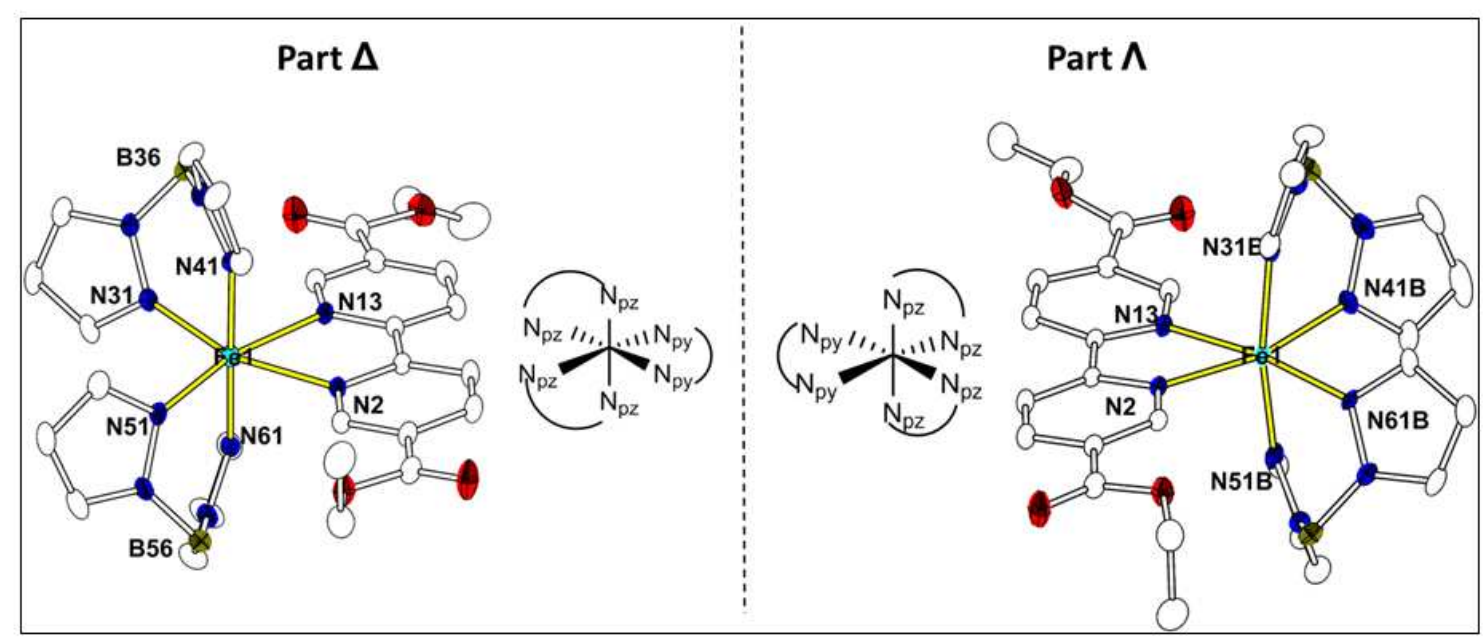

Figure 3. Perspective view of the molecular structures of enantiomers in 3 at $296 \mathrm{~K}$. Displacement ellipsoids are drawn at the $10 \%$ probability level and the $\mathrm{H}$ atoms have been omitted for the sake of clarity.

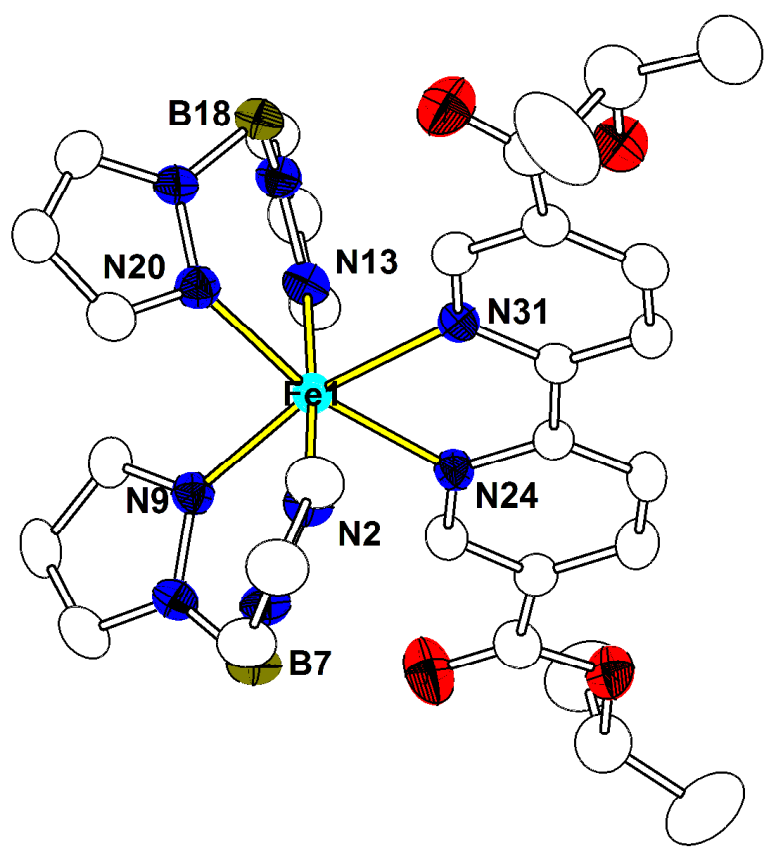

Figure 4. Perspective view of the molecular structures of 4 at $297 \mathrm{~K}$. Displacement ellipsoids are drawn at the $30 \%$ probability level and the $\mathrm{H}$ atoms have been omitted for the sake of clarity.

X-ray crystallographic analysis at both high (296 K) and low temperatures (92 and 20 $\mathrm{K})$ reveals that 3 shows a significant disorder of the boron containing pyrazolyl ligand, denoted as Part $\Delta$ and Part $\Lambda$, which are enantiomers (Figures 3 and S4). The 
disorder can be viewed as being generated by applying a mirror plane along the EtObpydc ligand or perpendicular to it. All $\mathrm{Fe}^{\prime l}$ ions are in a distorted $\mathrm{FeN}_{6}$ octahedral coordination environment derived from one EtObpydc ligand and two $\left(\mathrm{H}_{2} \mathrm{Bpz}_{2}\right)^{-}$anions. Comparison of structural data at different temperatures reveals that the average Fe- $\mathrm{N}_{\mathrm{pz}}$ bond length variation is $\Delta \mathrm{R} \sim 0.135 \AA$ in Part $\Delta$ whereas in Part $\Lambda$, the mean value $\Delta R<0.055 \AA$ (Table S2). Such considerable reorganization of molecular geometry corresponds to a temperature-driven spin transition in Part $\Delta$. Careful inspection of the packing arrangement reveals a 1D supramolecular chain generated by short interligand $\mathrm{C}-\mathrm{H} \cdots \mathrm{O}$ contacts $\left(\mathrm{C} 28-\mathrm{H} 28 \cdots \mathrm{O} 1^{*}\right.$, symmetry code:*, $1+x, y, 1+z$, Table S3) within the complex units (Figure 5).

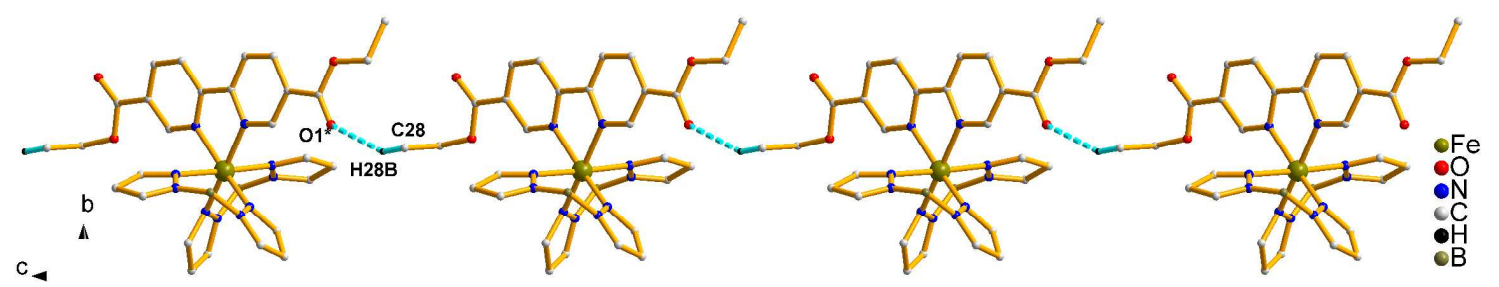

Figure 5. Crystal packing for 3 showing intermolecular $\mathrm{C}-\mathrm{H} \cdots \mathrm{O}$ interactions (C28H28B $\cdots O 1^{*}$, symmetry code*: $-1+x, y, 1+z$, blue dashed line). The molecules in part $\Lambda$ have been omitted for the sake of clarity.

Needle-shaped crystal of 4 (Figure 5) crystallize in the orthorhombic Pbca space group with the expected formula of $\left[\mathrm{Fe}\left(\mathrm{H}_{2} \mathrm{~B}(\mathrm{pz})_{2}\right)(\boldsymbol{i}\right.$-PrObpydc)]. The central skeleton is isomorphous to 1 , thus revealing a mononuclear complex (Figure 2). The crystal structure was determined at both 297 and $90 \mathrm{~K}$ to study the reorganization of the coordination geometry expected in the case of a HS $\leftrightarrow$ LS transition. The mean value of the Fe-N variation is found to be $0.194 \AA$, which lies within the expected range for $S=2 \leftrightarrow S=0$ transitions in Fe" $N_{6}$ SCO systems. ${ }^{10,13 a, 22}$ A detailed structure analysis reveal that a larger decrease is observed compared to for $\mathrm{Fe}-\mathrm{N}_{\mathrm{py}}$ distances $(0.25 \AA)$ as compared to Fe- $\mathrm{N}_{\mathrm{pz}}$ distances $(0.17 \AA)$ after a spin transition which may be mainly accounted for by the fact that such bipy-type ligand acts as a better $\pi$-electron acceptor than pyrazolyl ligands. ${ }^{10}$ Short interligand contacts involve two types of $\mathrm{CH} \cdots \mathrm{O}$ interactions, $\mathrm{C} 11-\mathrm{H} 11 \cdots \mathrm{O} 43^{*}$ and $\mathrm{C} 35-\mathrm{H} 35 \cdots \mathrm{O} 37^{\#}$ (symmetry code: *, 1.5-x, 0.5+y, z; * -1.5+x, 0.5-y, 1-z; Table S4) (Figure 6, top and Figure S5) that give rise to a $2 \mathrm{D}$ supramolecular framework (Figure 6 , bottom). 

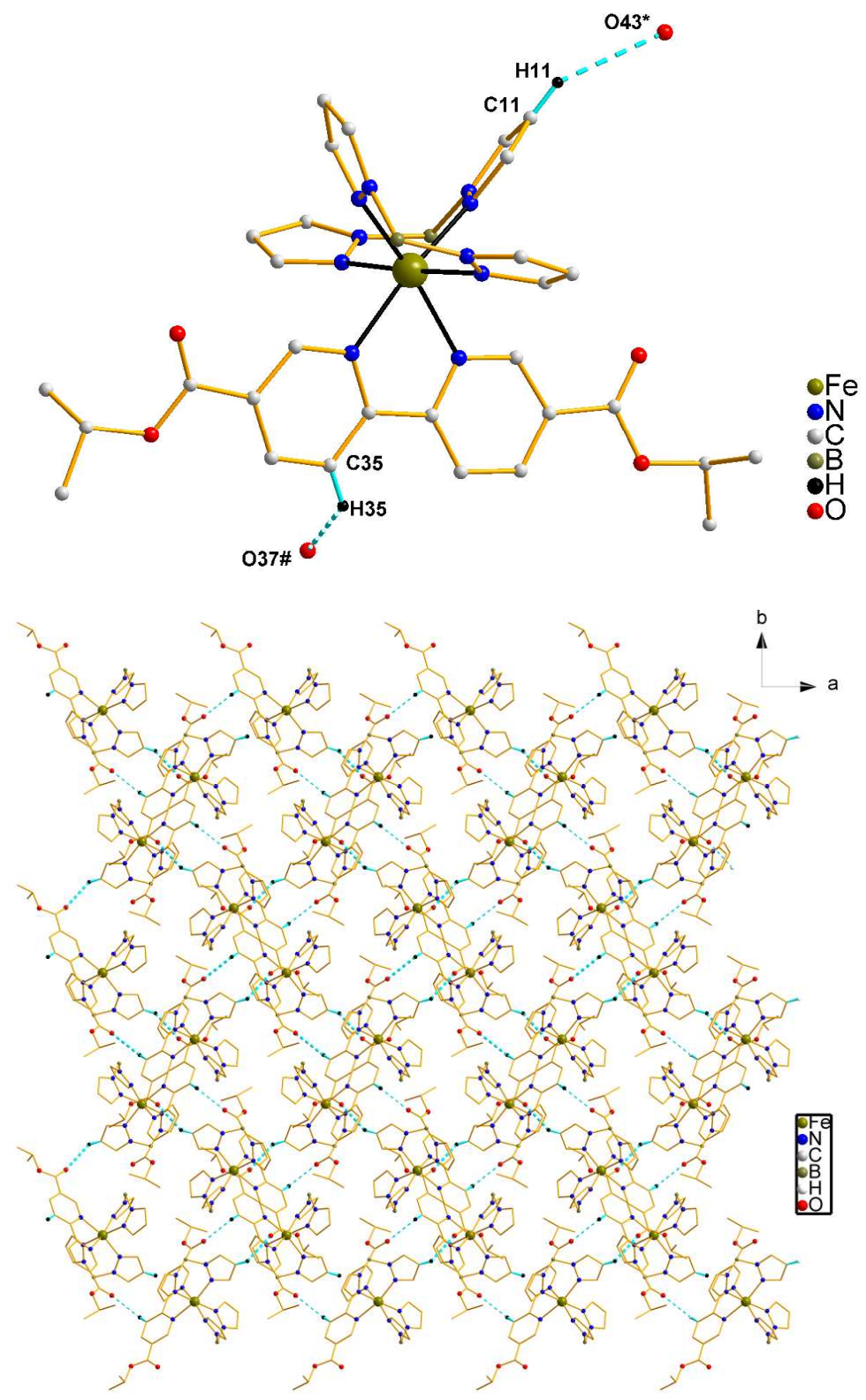

Figure 6. Packing diagram of 4 showing: (top) two types of intermolecular $\mathrm{C}-\mathrm{H} \cdots \mathrm{O}$ interactions ( $\mathrm{C} 11-\mathrm{H} 11 \cdots \mathrm{O} 43^{*}$ and $\mathrm{C} 35-\mathrm{H} 35 \cdots \mathrm{O} 37^{*}$ (symmetry code: * $1.5-\mathrm{x}, 0.5+\mathrm{y}, \mathrm{z}$; \#, -1.5+x, 0.5-y, 1-z; blue dashed line); (bottom) 2D supramolecular framework. 

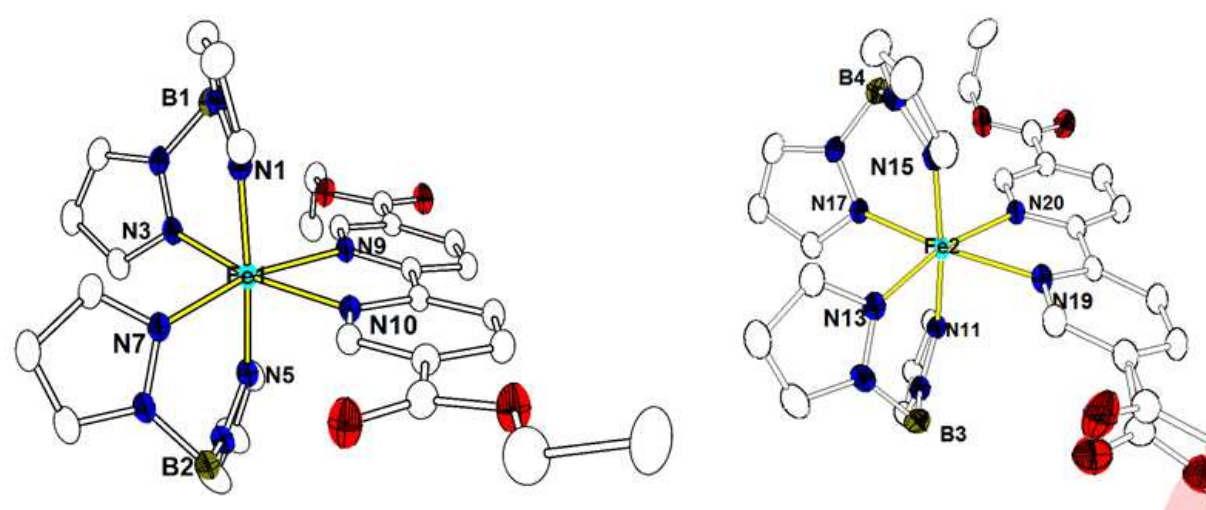

Figure 7 Crystal structure of 3B at $150 \mathrm{~K}$. Displacement ellipsoids are drawn at the $30 \%$ probability level and the $\mathrm{H}$ atoms have been omitted for the sake of clarity. The red circle shows the terminal ethyl acetate group in a disordered state with an occupancy factor of $21 \%$ whereas an unexpected methyl acetate group is detected with an occupancy factor of $79 \%$.

Unexpected crystal structures of $3 B$ and 4B. Increasing crystallization time afforded translucent dark green prism crystals which were formed after one week. The crystal structure determination revealed however for both complexes, denoted 3B and 4B, respectively, an unexpected ligand impurity, as shown in Figures 7 and 9, which will be discussed below.

Complex 3B crystallizes in the monoclinic space group $P 2_{1} / C$ with two crystallographically independent sites denoted Fe1 and Fe2 (Figure 7). The Fe1 site is composed of one bidentate ligand EtObpydc and two $\left(\mathrm{H}_{2} \mathrm{Bpz}_{2}\right)^{-}$anions, leading to a $\mathrm{FeN}_{6}$ coordination sphere, similar to the one found in 1 . The situation is dramatically different for the $\mathrm{Fe} 2$ site which reveals one terminal ethyl acetate group in a disordered state with an occupancy factor of $21 \%$ whereas an unexpected methyl acetate group is detected with an occupancy factor of $79 \%$ (Figure 7 ). It is worth noting that the disorder of the terminal acetate group has significant effect on the $\mathrm{Fe}^{\prime l}$ environment, especially on $\mathrm{Fe}-\mathrm{N}_{\mathrm{py}}$ bond length when considering its temperature dependence which was recorded down to $100 \mathrm{~K}$. Indeed, the average Fe- $\mathrm{N}_{\text {py }}$ bond length for the Fe1 molecule $(\sim 2.194 \AA)$ was found to be slightly shorter than that of Fe2 molecule $\left(\sim 2.243 \AA\right.$ ) at $100 \mathrm{~K}$. Also, the Fe- $\mathrm{N}_{\text {py }}$ bond length in the Fe1 molecule is found to decrease with temperature contrary to the Fe2 molecule 
(Figure 8). This behavior call for a partial thermally induced SCO for one iron(II) site, which should lead to an incomplete SCO, a result will be confirmed by magnetic measurements (vide infra).

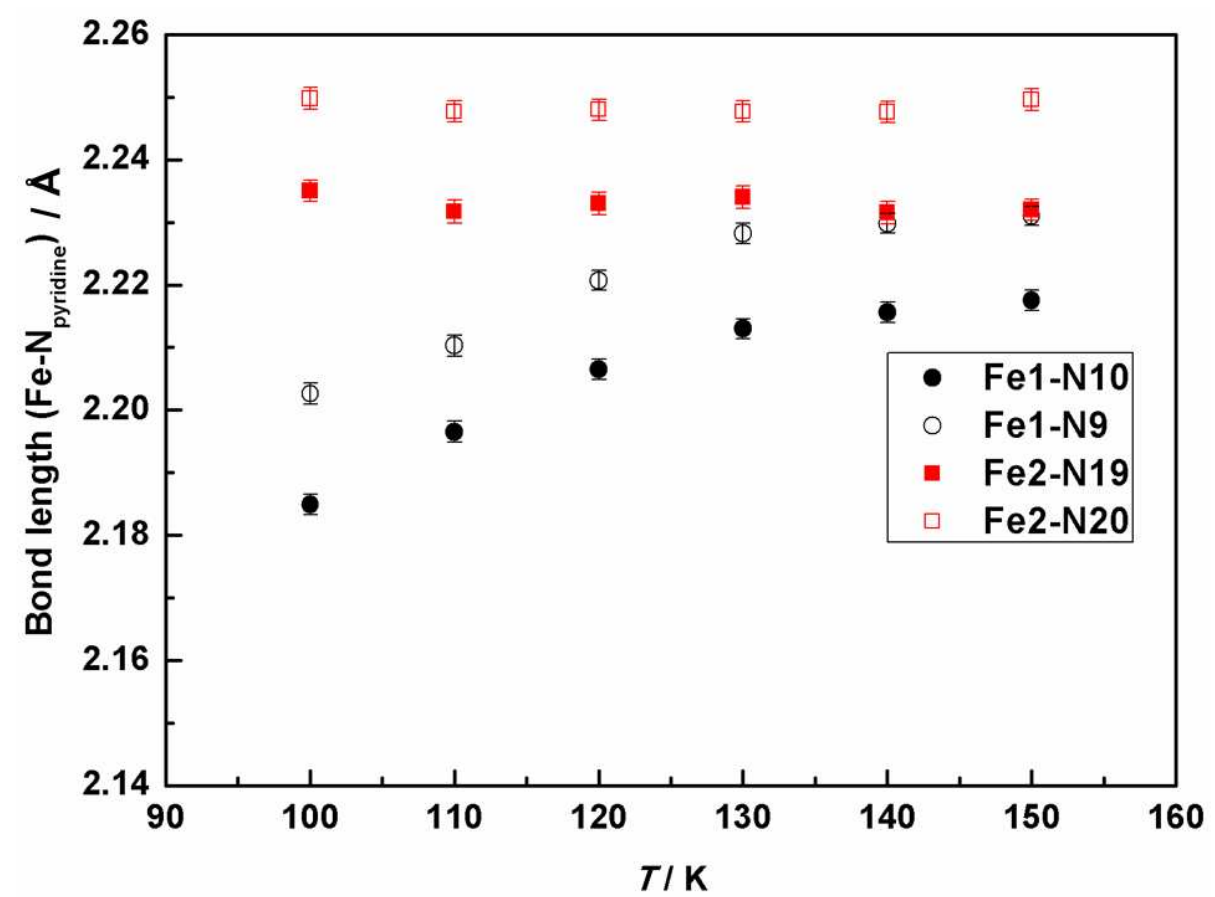

Figure 8. The $\mathrm{Fe}-\mathrm{N}_{\mathrm{py}}$ bond lengths $v$ s. temperature for $\mathbf{3 B}$ considering $\mathrm{Fe} 1$ and $\mathrm{Fe} 2$ sites. Whereas no dependence is detected for the $\mathrm{Fe} 2$ site, a smooth decrease in the bond lengths is found for the $\mathrm{Fe} 1$ site.

The crystal structure of 4B was solved at $175 \mathrm{~K}$ in the monoclinic space group $P 2_{1} / C$. Two crystallographically independent units, $\mathrm{Fe} 1$ and $\mathrm{Fe} 2$, are identified (Figure 9). Both $\mathrm{Fe} 1$ and $\mathrm{Fe} 2$ molecules consist of an $\mathrm{Fe}$ atom surrounded by one bidentate bipy-typed ligand and two $\left(\mathrm{H}_{2} \mathrm{Bpz}_{2}\right)^{-}$anions with a $\mathrm{Fe}-\mathrm{N}$ bond distance of 2.139(2)2.251(2) $\AA$, indicative of a HS Fe" state (Figure 9). 

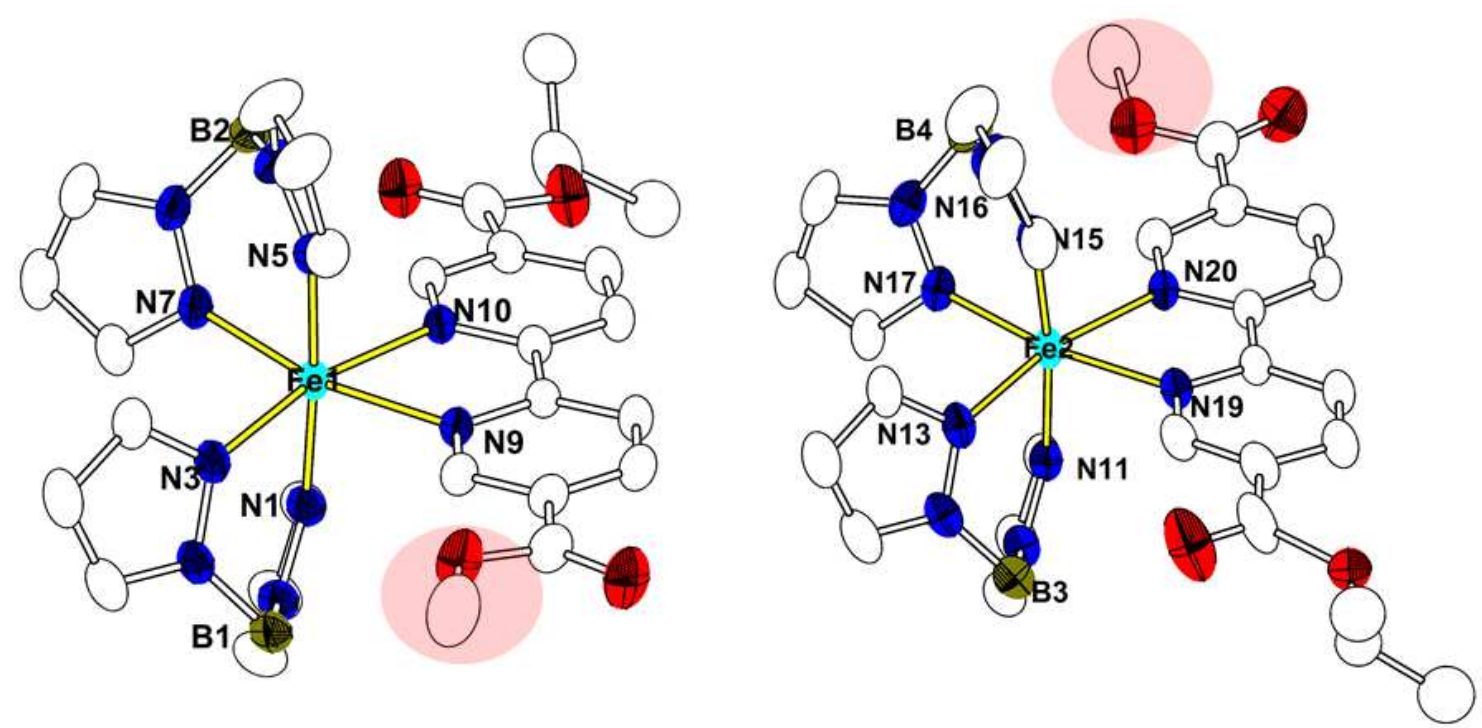

Figure 9. Crystal structure of 4B at $175 \mathrm{~K}$. Displacement ellipsoids are drawn at the $30 \%$ probability level and $\mathrm{H}$ atoms have been omitted for the sake of clarity. The red circle shows the unexpected methyl acetate group.

To our surprise, a closer look at the $\mathrm{FeN}_{6}$ environment reveals that the original $i$ PrObpydc ligand has been completely changed into a new asymmetrical ligand ' ${ }^{\prime}$, where L' is 5-isopropyl 5'-methyl-2,2'-bipyridine-5,5'-dicarboxylate (Scheme 3). Since the EtObpydc and $\boldsymbol{i}$-PrObpydc ligands used for the synthesis of $\mathbf{3}$ and $\mathbf{4}$, were free of any impurities, we thought that a transesterification ${ }^{23}$, could occur during the crystallization process. This reaction would be catalyzed by a Fe $\mathrm{F}^{\text {III }}$ impurity provided by the Fe" salt used during the synthesis, which would be partially oxidized into Fe"ll. This impurity would be favored in case a slight excess of $\mathrm{Fe}\left(\mathrm{ClO}_{4}\right)_{2}$ would be present in the reaction medium so that the residual of $\mathrm{Fe}^{\text {III }}$ would run as a catalyst to induce the transesterification from the original iso-propyl group into a methyl group via the $\mathrm{MeOH}$ solvent. This process would be more probable in case of a slow reaction, such as a crystallization by slow evaporation.

Scheme 3. Suggested formation mechanism for 4B

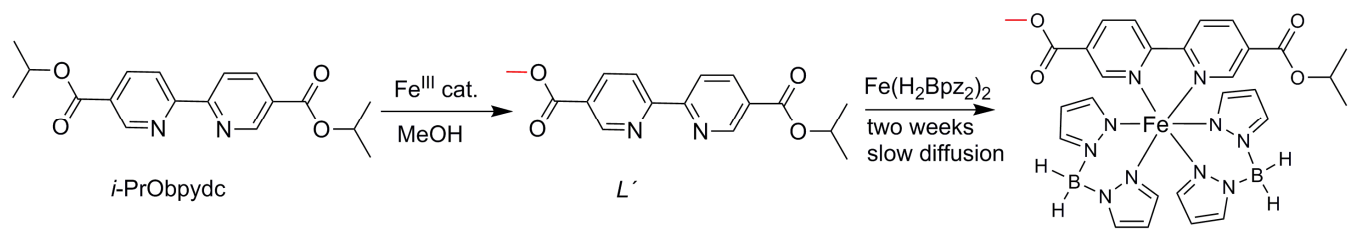

\subsection{Spectroscopic and magnetochemical studies}


UV-vis diffuse reflectance spectroscopy (DRS). In the solid state, all the powder samples 1-4 are strongly thermochromic. At room temperature, complex 1 is pink while other three complexes are green. On cooling, the color changes to deep red for 1 and deep green for 2, 3 and 4. For instance, 4 exhibits reversible pronounced thermochromism from green to dark green on quenching of the sample in liquid nitrogen for several seconds (Figure 10). The visible change in color is due essentially to a shift of the charge-transfer transition to lower energy at low temperature.

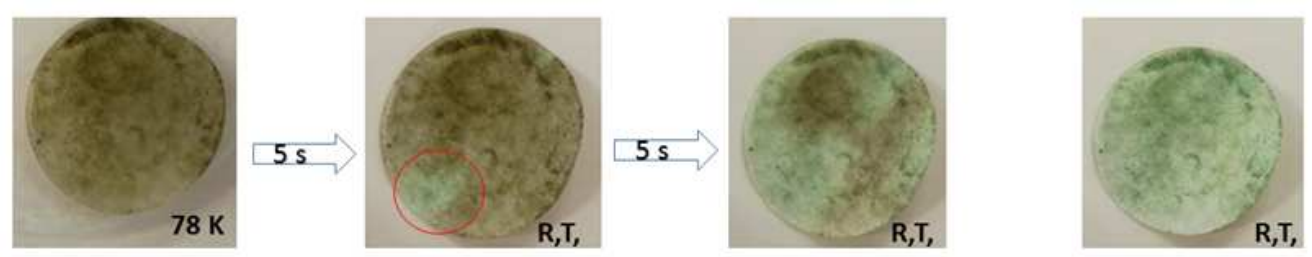

Figure 10. Illustration of thermochromism of powder sample 4 after quench cooling the sample to liquid nitrogen from dark green to green within several seconds.

As observed in Figure 11, a broad-band centred at $\sim 11800 \mathrm{~cm}^{-1}$ for 1 can be assigned to a metal-to-ligand charge transfer (MLCT) adsorption from the metal $d_{\pi^{-}}$ orbitals into $\pi^{*}$-orbitals of the ligands. ${ }^{7,24}$ For the other three complexes, such ligand field absorption is shifted to higher energy and further split into the principal component occurring around $14000 \mathrm{~cm}^{-1}$ with a shoulder at $12000 \mathrm{~cm}^{-1}$. The splitting arises presumably from Jahn-Teller and/or low symmetry effects associated to the ${ }^{5} T_{2 g} \rightarrow{ }^{5} E_{g}$ transition. ${ }^{7}$ Additionally, the position of the MLCT band changes from the methyl group to the alky acetate series. This indicates that the introduction of an electron-withdrawing alky acetate group leads to an increase in the $\pi$-accepting ability of the ligand bipy-type ${ }^{16}$ thus influencing the SCO behaviour.

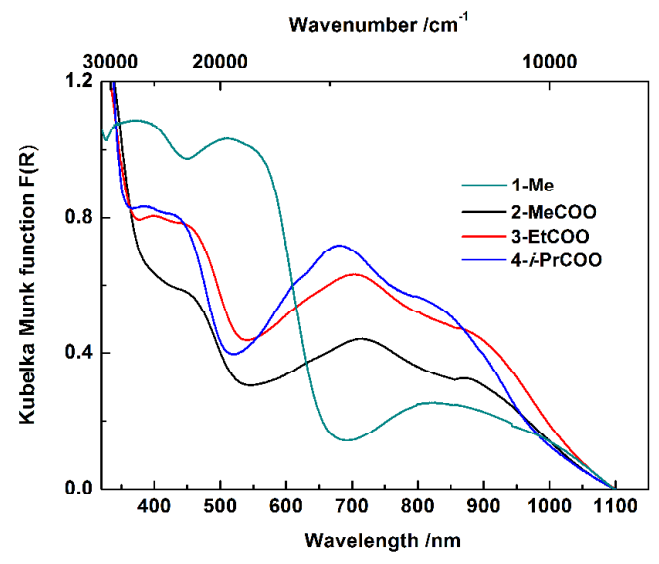


Figure 11. UV-vis DRS of powdered samples 1-4 recorded at room temperature.
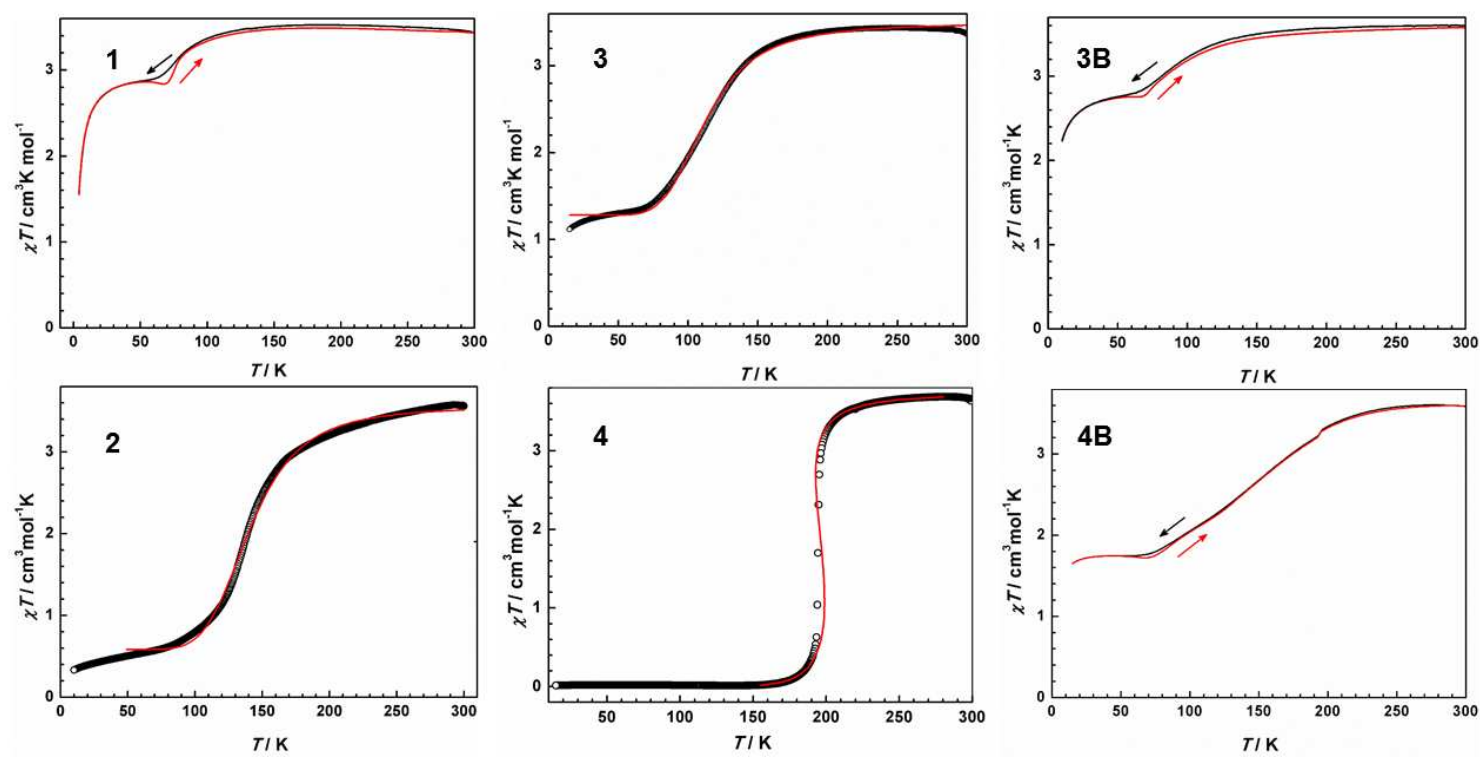

Figure 12. Temperature-dependent $X_{M} T$ plot for all the complexes. The red line for $\mathbf{1}$, 3B and 4B shows the heating mode. The red solid curve corresponds to data fitting using the ideal solution mode $\left.\right|^{25}$ for $\mathbf{2}$ and $\mathbf{3}$ and Slichter and Drickamer model ${ }^{26}$ for $\mathbf{4}$.

Magnetic properties. The solid-state magnetic behavior of all the complexes was probed by variable-temperature direct current (dc) susceptibility measurements on polycrystalline samples under an applied field of $1 \mathrm{~T}$. The room temperature $X_{\mathrm{M}} T$ values of all complexes except 2 and $4 \mathrm{~B}$ ranging around $3.5 \mathrm{~cm}^{3} \mathrm{~K} \mathrm{~mol}^{-1}$ are consistent with pure non-interacting HS Fe" species. Upon cooling, however, different thermal evolutions are recorded as shown in Figure 12.

Complex 1 shows rather unusual magnetic properties. Upon cooling, no dramatic variation is observed down to ca. $150 \mathrm{~K}$, after which a decrease is noticed to drop around $77 \mathrm{~K}$ to reach a plateau below $55 \mathrm{~K}$. The sharper decrease observed below $25 \mathrm{~K}$ is likely due to zero-field splitting of a large fraction of $\mathrm{HS} \mathrm{Fe}$ il ions. On warming, no hysteresis loop is detected but a small decrease of the $X_{\mathrm{M}} T$ product on warming is noticed, just before the transition temperature of $77 \mathrm{~K}$. This behaviour presumably calls for a freezing-in effect ${ }^{27}$, that hinders further the spin conversion. ${ }^{57} \mathrm{Fe}$ Mössbauer spectroscopy (vide infra), carried out on the same sample batch, confirms the incomplete character of the SCO behaviour with ca. 9.5\% of LS Fe" ions being detected at $78 \mathrm{~K}$. The magnetic properties of 3B resemble the one of 1 with a gradual type transition involving a few spin carriers. Mössbauer spectroscopy informs that $83.3 \%$ of $\mathrm{HS} \mathrm{Fe}$ "ions are populated at $78 \mathrm{~K}$ (vide infra). 
Complex 2 undergoes a gradual and almost complete SCO behavior. Indeed, the thermal evolution of $X_{M} T$ continuously decreases from ambient temperature to $170 \mathrm{~K}$, from which it drops to $0.59 \mathrm{~cm}^{3} \mathrm{~K} \mathrm{~mol}^{-1}$ at $80 \mathrm{~K}$, reaching $0.33 \mathrm{~cm}^{3} \mathrm{~K} \mathrm{~mol}^{-1}$ at $10 \mathrm{~K}$. The SCO profile can be fitted well using the ideal solution model ${ }^{25}$, leading to $T_{1 / 2}=$ 140.4(2) $\mathrm{K}$, enthalpy $\Delta H_{\mathrm{HL}}=8.18(9) \mathrm{kJ} \mathrm{mol}^{-1}$ and entropy $\Delta S_{\mathrm{HL}}=58.4(5) \mathrm{J} \mathrm{K}^{-1} \mathrm{~mol}^{-1}$.

For 3 , the $X_{\mathrm{M}} T$ value keeps a nearly constant evolution at $3.36 \mathrm{~cm}^{3} \mathrm{~K} \mathrm{~mol}^{-1}$ in the temperature range $300-210 \mathrm{~K}$, after which it decreases gradually, disclosing a $\mathrm{HS} \rightarrow$ LS conversion with $T_{1 / 2}=113 \mathrm{~K}$, and reaching a second plateau at $1.28 \mathrm{~cm}^{3} \mathrm{~K} \mathrm{~mol}^{-1}$ over the range $20-60 \mathrm{~K}$, indicative a nearly half-spin transition. No change was observed while recording again the magnetic properties over the range 20-300 K. Fitting the magnetic data using the ideal solution model ${ }^{25}$, provides the following thermodynamic parameters associated to the SCO: $\Delta H_{\mathrm{HL}}=5.90(6) \mathrm{kJ} \mathrm{mol}^{-1}, \Delta S_{\mathrm{HL}}=$ 52.2(4) $\mathrm{J} \mathrm{K}^{-1} \mathrm{~mol}^{-1}$ as well as $T_{1 / 2}=113.4(2) \mathrm{K}$.

For 4 , the $X_{\mathrm{M}} T$ value slowly decreases from $3.60 \mathrm{~cm}^{3} \mathrm{~K} \mathrm{~mol}^{-1}$ at $300 \mathrm{~K}$ to $3.04 \mathrm{~cm}^{3}$ $\mathrm{K} \mathrm{mol}^{-1}$ at $200 \mathrm{~K}$ and then drops steeply at $T_{1 / 2}=194 \mathrm{~K}$ to reach to $0.01 \mathrm{~cm}^{3} \mathrm{~K} \mathrm{~mol}^{-1}$ at $15 \mathrm{~K}$. Such behavior indicates an abrupt spin transition from a HS state $(S=2)$ at high temperature to a LS ground state $(S=0)$ at lower temperature. Fitting the

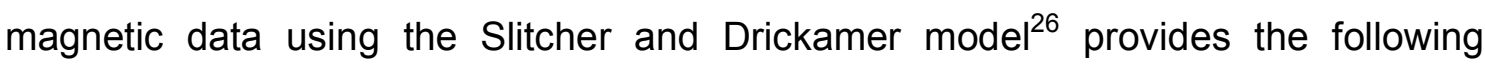
thermodynamic parameters: $\Delta H_{\mathrm{HL}}=12.5(1) \mathrm{kJ} \mathrm{mol}^{-1}, \Delta \mathrm{S}_{\mathrm{HL}}=63.6(4) \mathrm{J} \mathrm{K}^{-1} \mathrm{~mol}^{-1}, \Gamma=$ $4.16(4) \mathrm{kJ} \mathrm{mol}^{-1}$ and $T_{1 / 2}=195.9(1) \mathrm{K}$. Such later value nicely corresponds to the recorded transition temperature.

The temperature dependence of the magnetic properties of $4 \mathrm{~B}$ resembles the one of 3 with a gradual spin crossover profile which plateau at $1.73 \mathrm{~cm}^{3} \mathrm{~K} \mathrm{~mol}^{-1}$ over the range 20-60 K. Mössbauer spectroscopy informs that ca. $48 \%$ of $\mathrm{HS} \mathrm{Fe}^{\prime \prime}$ ions are populated at $78 \mathrm{~K}$ (vide infra). Thus, a gradual half-spin conversion was described. Noteworthy is that a knot was detected at $195 \mathrm{~K}$ which exactly corresponds to $T_{1 / 2}$ observed in 4 (Figure S6). This feature suggests that the transesterification is not complete with a residual amount of $\mathbf{4}$ upon increasing crystallization time to one week. 


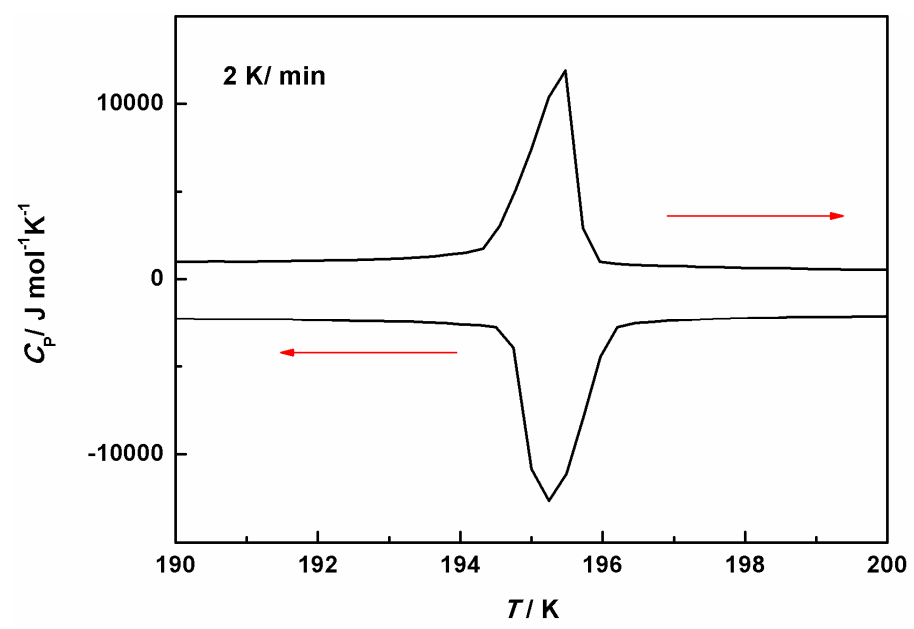

Figure 13. Heat capacity thermal profile on cooling and warming modes of 4 recorded at a scan rate of $2 \mathrm{~K} / \mathrm{min}$.

Differential Scanning Calorimetry (DSC). Given the sharp spin transition identified for 4 , this complex was also investigated by differential scanning calorimetry (DSC) on both warming and cooling modes at a $2 \mathrm{~K} \mathrm{~min}^{-1}$ scan rate. Corresponding heat capacity temperature profiles, $C_{p}$, are displayed in Figure 13. One exothermic peak, characteristic of a first order phase transition, is identified on cooling at $T_{\text {max }}{ }^{\downarrow}=195.5$ K. On warming, an endothermic peak is observed at $T_{\max }{ }^{\uparrow}=195.5 \mathrm{~K}$, thus delineating no hysteresis effect. The variations of enthalpy $\left(\Delta H_{H L}\right)$ and entropy $\left(\Delta S_{H L}\right)$ have been determined as $\Delta H_{\mathrm{HL}}=11.9 \mathrm{~kJ} \mathrm{~mol}^{-1}$ and $\Delta S_{H L}=60.7 \mathrm{~J} \mathrm{~K}^{-1} \mathrm{~mol}^{-1}$. These values are within the experimental range for Fe" SCO systems ${ }^{28}$. The entropy gain is found to be much larger than the electronic contribution to the entropy, $R \cdot \ln (5)=13.4 \mathrm{~J}$ $\mathrm{K}^{-1} \mathrm{~mol}^{-1}$, for $\mathrm{Fe}^{\text {II SCO complexes. }}{ }^{29}$ This is due to a high extent to the vibrational entropy which was identified as $47.3 \mathrm{~J} \mathrm{~K}^{-1} \mathrm{~mol}^{-1}$.

Table $1{ }^{57} \mathrm{Fe}$ Mössbauer parameters for all the complexes

\begin{tabular}{|c|c|c|c|c|c|c|c|c|c|c|c|}
\hline \multirow[t]{2}{*}{ Complex } & \multirow[t]{2}{*}{$\mathrm{T} / \mathrm{K}$} & \multirow[t]{2}{*}{$\mathrm{A}_{\mathrm{HS}} / \mathrm{A}_{\mathrm{tot}}(\%)$} & \multicolumn{3}{|c|}{$\mathrm{HS} \mathrm{Fe}^{\|}(\mathrm{mm} / \mathrm{s})$} & \multicolumn{3}{|c|}{$\mathrm{Fe}^{\|} \mathrm{LS}(\mathrm{mm} / \mathrm{s})$} & \multicolumn{3}{|c|}{$\mathrm{Fe}^{\mathrm{III}}(\mathrm{mm} / \mathrm{s})$} \\
\hline & & & $\delta$ & $\Delta E_{Q}$ & $\Pi 2$ & $\delta$ & $\Delta E_{Q}$ & $\Pi 2$ & $\delta$ & $\Delta E_{Q}$ & $\Pi 2$ \\
\hline \multirow[t]{2}{*}{$1^{\mathrm{a}}$} & 298 & 100 & 1.01(4) & $1.84(8)$ & $0.15(6)$ & & & & & & \\
\hline & 78 & $90.5(3)$ & 1.12(4) & $2.53(8)$ & $0.15(8)$ & $0.50(1)$ & $0.33(2)$ & $0.23(2)$ & & & \\
\hline \multirow[t]{2}{*}{$2^{b}$} & 298 & $88.3(5)$ & 1.01(1) & $2.41(3)$ & $0.25(3)$ & $0.49(2)$ & $0.71(1)$ & $0.19(1)$ & & & \\
\hline & 78 & $21(2)$ & 1.12(1) & $3.11(3)$ & $0.20(3)$ & $0.48(3)$ & $0.65(5)$ & $0.17(6)$ & & & \\
\hline \multirow[t]{2}{*}{$3^{a}$} & 298 & 100 & 1.01(3) & $2.00(5)$ & $0.23(4)$ & & & & & & \\
\hline & 78 & $46.9(2)$ & $1.12(6)$ & $2.76(1)$ & $0.16(9)$ & $0.50(5)$ & $0.55(9)$ & $0.16(7)$ & & & \\
\hline \multirow[t]{2}{*}{$4^{\mathrm{a}}$} & 298 & 100 & $0.99(5)$ & $1.80(1)$ & $0.16(8)$ & & & & & & \\
\hline & 78 & 0 & & & & $0.48(3)$ & $0.66(5)$ & $0.16(3)$ & & & \\
\hline \multirow[t]{2}{*}{$3 \mathrm{~B}^{\mathrm{a}}$} & 298 & 100 & $1.02(8)$ & $1.99(2)$ & $0.23(1)$ & & & & & & \\
\hline & 78 & 83.3(1) & $1.12(2)$ & $2.68(4)$ & $0.17(3)$ & $0.50(1)$ & $0.57(2)$ & $0.16(2)$ & & & \\
\hline \multirow[t]{2}{*}{$4 \mathrm{~B}^{\mathrm{a}}$} & 298 & $63.4(5)$ & $1.00(1)$ & $2.21(3)$ & $0.19(2)$ & & & & $0.33(4)$ & $0.65(7)$ & $0.26(5)$ \\
\hline & 78 & $47.8(6)$ & 1.12(3) & $2.64(7)$ & $0.30(5)$ & $0.49(2)$ & $0.71(3)$ & $0.23(2)$ & & & \\
\hline
\end{tabular}


$\delta$ : isomer shift (with respect to $\alpha-\mathrm{Fe}$ at $298 \mathrm{~K}$ ); $\Delta \mathrm{E}_{\mathrm{Q}}$ : quadrupole splitting: $\Gamma / 2$ : half width at half maximum. a: grounded crystals; b: powder sample.

${ }^{57} \mathrm{Fe}$ Mössbauer spectroscopy. Temperature-dependent zero-field ${ }^{57} \mathrm{Fe}$ Mössbauer spectroscopy was applied to investigate the stability of our materials (oxidation of iron) and to determine the nature of spin states at low and high temperatures (Figures 14 and S7). As shown in Table 1, all the complexes display an isomer shift $(\delta)$ of $\sim 1 \mathrm{~mm}$ $\mathrm{s}^{-1}$ at room temperature. An identical room temperature isomer shift was found for the mononuclear SCO complex $\left[\mathrm{Fe}\left(\mathrm{H}_{2} \mathrm{~B}(\mathrm{pz})_{2}\right)_{2} \mathrm{phen}^{*}\right]$, where phen* is a diarylethenederived phenanthroline ligand ${ }^{13 a}$. The listed Mössbauer parameters point unambiguously to the presence of $\mathrm{HS} \mathrm{Fe} " \mathrm{~N}_{6}$ species at room temperature. For 2, LS $\mathrm{Fe}(\mathrm{II})$ ions with an isomer shift $(\delta)$ of $0.49 \mathrm{~mm} \mathrm{~s}^{-1}$ are in addition identified whereas for 4B, Fe(III) species reflected by an isomer shift $(\delta)$ of $0.33 \mathrm{~mm} \mathrm{~s}^{-1}$ are revealed at room temperature (Figure S7). Upon cooling to $78 \mathrm{~K}$, the isomer shift increases to $\delta=$ $1.12 \mathrm{~mm} \mathrm{~s}^{-1}$ due to the expected second-order Doppler shift ${ }^{30}$, and the quadrupole splitting $\Delta E_{Q}$ becomes as large as $3.11 \mathrm{~mm} \mathrm{~s}^{-1}$ for 2 . More importantly, a new quadrupole doublet appears for all the complexes with a relative intensity of a full population for 4 , which is characterized by a lower isomer shift around $0.50 \mathrm{~mm} \mathrm{~s}^{-1}$ and a much smaller quadrupole splitting $\Delta E_{Q}<1.0 \mathrm{~mm} \mathrm{~s}^{-1}$. This later signal is characteristic for a LS $\mathrm{Fe}^{\mathrm{Il}}$ ion in a distorted pseudooctahedral environment. Incomplete SCO behavior is thus identified for 1, 2, 3, 3B and 4B contrary to 4 .
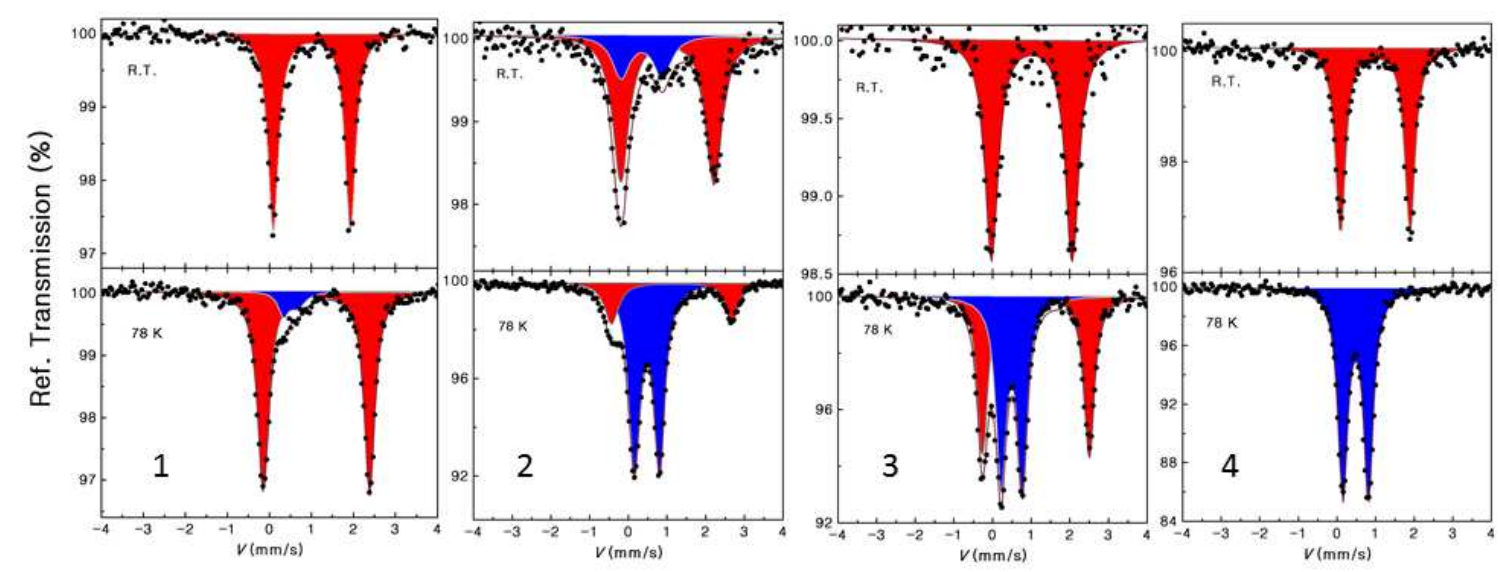

Figure $14{ }^{57} \mathrm{Fe}$ Mössbauer spectra of polycrystalline samples for all the complexes recorded at $298 \mathrm{~K}$ (top) and $78 \mathrm{~K}$ (bottom). Red and blue correspond to the Fe" HS and LS doublets, respectively.

DFT calculations. In order to probe the influence of electronic substituents on SCO, 
we carried out density functional calculations for complexes 1-4 using the ORCA 4.0.0. program $^{31}$. Geometry optimizations were started from the single crystal X-ray structure data using the BP86 functional in combination with the def2-SVP basis set on all atoms with the exception of Fe, for which the triple- $\zeta$ def2-TZVP basis set was used. The HS state for 1 can be attributed to the relatively small energy difference $(\Delta)$ between the highest $d_{\pi}$-orbital and the $d_{z}{ }^{2}$-orbital, while the series 2 to 4 bearing different ester group turned out to reveal a relatively large energy splitting of $\Delta$ and stronger $\pi$-acceptor properties, which stabilized the LS state ${ }^{16}$ (Figures S8-S12). Within the series 2 to $\mathbf{4}$, however, the difference between the ligand field strengths of the various acetate ligands is negligible (Figure S8), which indicates that the crystal packing plays an important role in switching the $\mathrm{SCO}^{14}$ (vide infra).

\section{DISCUSSION}

In our system, the SCO behavior is drastically different from complexes to complexes caused by subtle but crucial structural differences between the respective $\mathrm{Fe}^{\|} \mathrm{N}_{6}$ skeleton. It is well known that the prototype of $\left[\mathrm{Fe}\left(\mathrm{H}_{2} \mathrm{Bpz}_{2}\right)_{2}\right.$ (bipy)] complex (5) has been reported to show thermally induced spin transition ${ }^{10}$. However, the introduction of different aromatic directing groups into the bipy ligand can affect the $\pi$-acceptor character, leading to the distinction of ligand field strength and diversity of SCO properties. ${ }^{16}$ As a typical electron withdrawing groups, ester moieties in 2, 3 and 4 are good candidates to support the bipy ligands acting as a better m-electron acceptor. This point has been reflected by the shorter Fe- $\mathrm{N}_{\mathrm{py}}$ distances (1.968(1) and 1.964(1) $\AA$ ) observed for 4 in the LS state compared to 5 (2.013(2) $\AA$ ). The BP86 calculations for the discussed complexes also revealed that the energy difference $(\Delta)$ between the highest $d_{\pi}$-orbital and the $d_{z}{ }^{2}$-orbital of $2.70 \mathrm{eV}$ for $\mathbf{2 , 3}$ and $\mathbf{4}$ is slightly larger than that of $2.67 \mathrm{eV}$ for 1 (Figure S8). Therefore, the introduction of electronwithdrawing substituents leads to strengthened ligand field strength of those ester series. On the other hand, crystal-packing effect has been shown to influence the magnetic properties of Fe" SCO complexes, illustrating explicitly the importance of the crystalline arrangement for realizing special cooperative behavior. Closer inspection between $\mathbf{3}$ and $\mathbf{4}$ crystal structures reveals main differences which can be summarized as follows:

(a) Supramolecular interactions: both crystal packing of $\mathbf{3}$ and $\mathbf{4}$ are dominated by $\mathrm{C}-\mathrm{H} \cdots \mathrm{O}$ interactions but with different supramolecular structures (Figures 5 and 6 ). 
3 displays a $\mathrm{C}_{\mathrm{sp}}{ }^{3}-\mathrm{H} \cdots \mathrm{O}$ interaction between carbonyl oxygen and ethyl $\beta$ carbon atom, which is located far away from iron(II) centers. 4, in turn, undergoes two kinds of C$\mathrm{H} \cdots \mathrm{O}$ interactions forming a 2D supramolecular structure. More importantly, both two types of proton donor in $\mathbf{4}$ originate from py and pz rings, which are directly coordinated to the $\mathrm{Fe}^{\| l}$ ion. Therefore, these $\mathrm{C}-\mathrm{H} \cdots \mathrm{O}$ interactions, as a catalog of weak $\mathrm{H}$-bonds, ${ }^{32}$ can shifts in electron density that accompany the magnitudes of the various components of the interaction energy to influence cooperative SCO behavior.
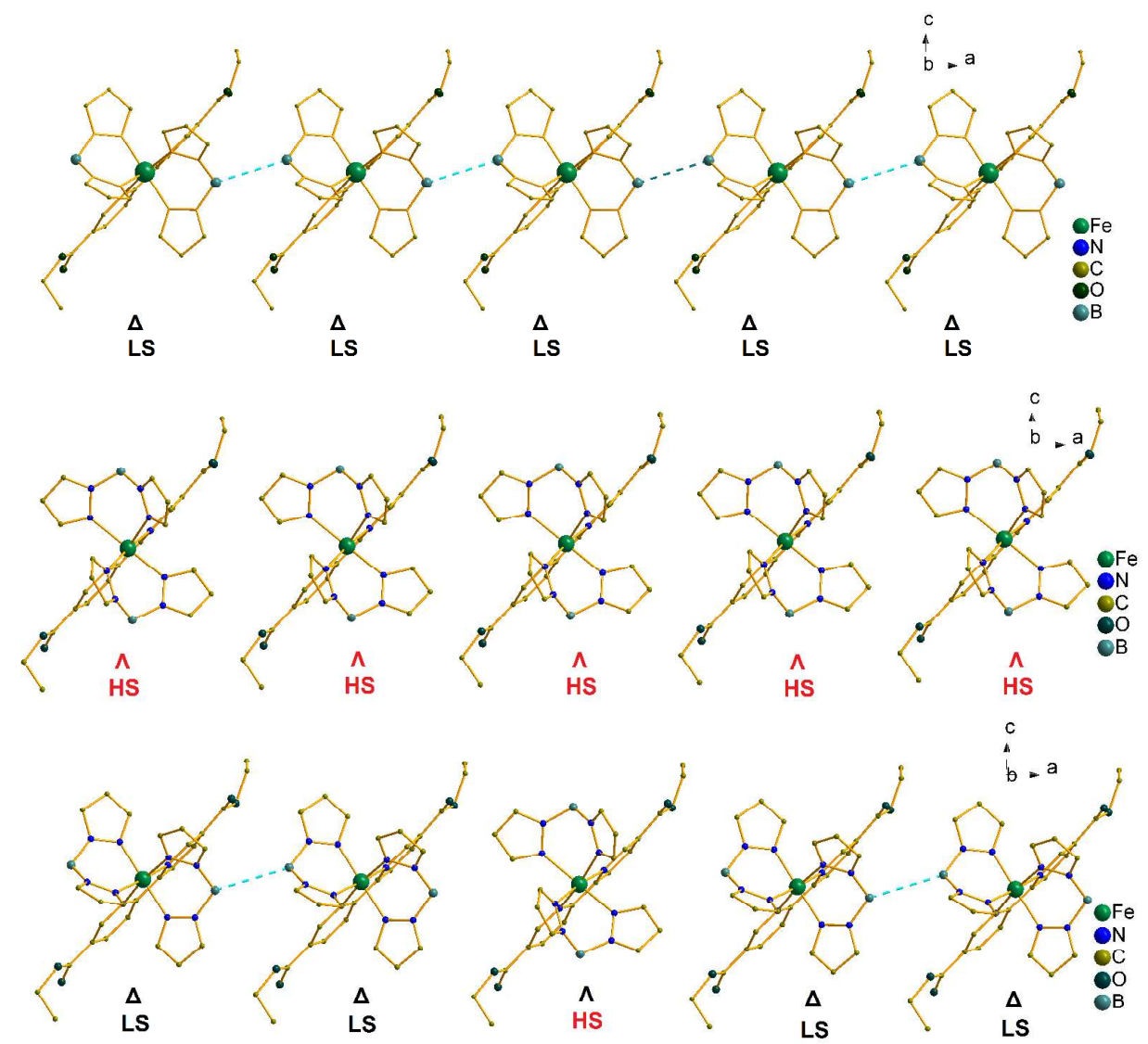

Figure 15. Illustration of the crystal packing for the $\Delta$ isomer with the ordered $\mathrm{H}_{2} \mathrm{Bpz}_{2}$ ligands (top), $\Lambda$ isomer with the ordered $\mathrm{H}_{2} \mathrm{Bpz}_{2}$ ligands (middle) and with the disordered $\mathrm{H}_{2} \mathrm{Bpz}_{2}$ ligands in $\mathbf{3}$ (bottom).

(b) Structural disorder: it is the disordered $\mathrm{H}_{2} \mathrm{Bpz}_{2}$ ligands in $\mathbf{3}$ which clearly affect the SCO properties between two different enantiomers. As shown in Figure 15, in ordered $\Delta$ isomers, there is a $B \cdots B$ short contact from the adjacent $\mathrm{H}_{2} \mathrm{Bpz}_{2}$ ligands at a distance of $3.626 \AA$. This $B \cdots B$ contact was strongly contracted as short as $3.475 \AA$ at $92 \mathrm{~K}$ and even to $3.452 \AA$ at $20 \mathrm{~K}$. Such contraction is observed for the first time for $\left[\mathrm{Fe}\left(\mathrm{H}_{2} \mathrm{Bpz}\right)_{2}(\mathrm{~L})\right]$ related complexes. In addition, to the best of our knowledge, this 
distance is the shortest $B \cdots B$ contact so far found for a ${ }_{\sim N}^{\sim N} N^{\mathrm{BH}_{2}} \cdots \mathrm{H}_{2} \mathrm{~B}_{N m}^{\mathrm{N} m}$ stacking motif, based on a CCDC search (Figure S13). The B.MB distances at low temperatures were much shorter than the Van der Waals radii of $B---B$ contact $(3.6-4.1 \AA)^{33}$, indicating a crowded stacking for the $\Delta$ configuration to a certain extent (Figure 15 , top). However, this crowded situation can be avoided by changing the $\Delta$ configuration to the $\Lambda$ one as shown in Figure 15, middle. Therefore, the disorder in $\mathbf{3}$ can be viewed as the insertion of $\Lambda$ molecules into the ordered $\Delta$ lattices, breaking down the boron contact of $\mathrm{H}_{2} \mathrm{Bpz}_{2}$ chain to a short range one (Figure 15, bottom). The LS molecules are conducted within these "crowded" short chains, while the HS molecules are kept in these disordered $\wedge$ species, because of their "roomy" surroundings. $\mathrm{Fe}^{\mathrm{II}}$ compounds showing incomplete or intermediate SCO have been reported $^{34}$, based on the hypothesis that SCO sites are strongly depends on cooperativity (hydrogen bonds, $\pi-\pi$ stacking, and van der Waals interactions within the crystal lattice), leading to a specific stoichiometric combination of HS and LS Fe" molecules. The cooperativity in disordered structure of $\mathbf{3}$ presented here, demonstrates that the control of chiral enantiomers within crystal packing can become an outlet for development of new molecular devices based on SCO materials

\section{CONCLUSION}

The foregoing results demonstrate that subtle, remote variation of the ligand field can lead to significant modulation of the transition temperature in $\left[\mathrm{Fe}\left(\mathrm{H}_{2} \mathrm{Bpz}_{2}\right)_{2}\right.$ (bipy-type)] SCO complexes with electronic substituent-decorated 5,5'-positioned bipy ligands. Importantly, the electronic substituent effect isopropyl acetate group and $\mathrm{C}-\mathrm{H} \cdots \mathrm{O}$ supramolecular interactions in $\mathbf{4}$ contribute to efficient elastic interactions associated to the spin crossover behavior, leading to an abrupt thermally induced spin transition. This example thus pinpoints the importance of supramolecular interactions, to design highly cooperative SCO complexes, ${ }^{35}$ which is of key relevance for mononuclear complexes where no important cooperative effects are expected. ${ }^{36}$ The addition of electronegative atoms on the bipy ligands increase the low-lying m-acceptor characters, which are suitably oriented for interaction with the filled $d_{\pi}$ orbitals of the metal atom and therefore for strengthening the metal-ligand interaction. Further indepth studies including theoretical calculation on this system are required to 


\section{EXPERIMENTAL SECTION}

Syntheses. All chemicals were used as commercially obtained without further purification.

Synthesis of bipyridine derivatives. 2,2'-Bipyridine-5,5'-dicarboxylic acid (bpydc) ${ }^{17}$, dimethyl-2,2'-bipyridyl-5,5'-dicarboxylate (MeObpydc ${ }^{18}$, diethyl-2,2'-bipyridyl-5,5'dicarboxylate (EtObpydc) ${ }^{19}$ and diisopropyl-2,2'-bipyridine-5,5'-dicarboxylate (iPrObpydc) ${ }^{20}$ were prepared using literature procedures.

Synthesis of complexes 1-4: Syntheses were performed under $\operatorname{Ar}_{(g)}$ using Schlenk techniques.

$\left[\mathrm{Fe}\left(\mathrm{H}_{2} \mathrm{Bpz}\right)_{2}\left(\right.\right.$ bipy $\left.\left.-\mathrm{CH}_{3}\right)\right]$ (1). To a solution of $\mathrm{K}\left[\mathrm{H}_{2} \mathrm{~B}(\mathrm{pz})_{2}\right](160 \mathrm{mg}, 0.88 \mathrm{mmol})$ in methanol $(5 \mathrm{~mL})$ was added a solution of $\mathrm{Fe}\left(\mathrm{ClO}_{4}\right)_{2} \cdot 6 \mathrm{H}_{2} \mathrm{O}(160 \mathrm{mg}, 0.44 \mathrm{mmol})$ in methanol $(5 \mathrm{~mL})$. The formed $\mathrm{KClO}_{4}$ precipitate was removed by filtration, affording a yellow solution. A solution of bipy- $\mathrm{CH}_{3}(81 \mathrm{mg}, 0.44 \mathrm{mmol})$ in methanol $(10 \mathrm{~mL})$ was then added dropwise to the solution, causing an immediate color change to dark pink. After the solution was stirred for $2 \mathrm{~h}$ at room temperature, a pink precipitate was collected, washed with methanol, and dried under a stream of $\mathrm{N}_{2(\mathrm{~g})}$. Yield: $158 \mathrm{mg}$ (67\%). Anal. Calcd. for $1\left(\mathrm{C}_{24} \mathrm{H}_{28} \mathrm{~N}_{10} \mathrm{~B}_{2} \mathrm{Fe}\right)$ : C, 53.98; $\mathrm{H}, 5.28 ; \mathrm{N}, 26.23$. Found: C, 53.06; H, 5.15; N, 26.33. MS (FTMS+pESI): $\mathrm{m} / \mathrm{z}: 535.21$ [M $\mathrm{M}^{+}$. Single crystals of 1 were obtained by slow diffusion in methanol under $\operatorname{Ar}_{(\mathrm{g})}$, using a single-tube glass vessel. The bipy- $\mathrm{CH}_{3}$ in $\mathrm{CH}_{3} \mathrm{OH}$ was placed on the top of a $\mathrm{Fe}\left(\mathrm{H}_{2} \mathrm{~B}(\mathrm{pz})_{2}\right)_{2}$ methanolic solution. Pink-violet single crystals of $\left[\mathrm{Fe}\left(\mathrm{H}_{2} \mathrm{Bpz}\right)_{2}\left(\mathbf{b i p y}-\mathrm{CH}_{3}\right)\right](\mathbf{1})$, suitable for X-ray diffraction analysis, formed after one week.

[Fe( $\left.\mathrm{H}_{2} \mathrm{Bpz}_{2}\right)_{2}$ (MeObpydc)] (2). The same method as for 1 was followed using MeObpydc (120 mg, $0.44 \mathrm{mmol}$ ), which yielded to an olive-green precipitate of 2 . Yield: $165 \mathrm{mg}(60 \%)$. Anal. Calcd for $2\left(\mathrm{C}_{26} \mathrm{H}_{28} \mathrm{~N}_{10} \mathrm{~B}_{2} \mathrm{O}_{4} \mathrm{Fe}\right)$ : C, 50.20; $\mathrm{H}, 4.54 ; \mathrm{N}$, 22.52. Found: C, 51.73; H, 4.53; N, 20.71. MS (FTMS+pESI): $\mathrm{m} / \mathrm{z}: 623.19$ [' $\left.\mathrm{M}^{+}\right]$'. Attempts to crystallize complex 2 failed due to the poor solubility of MeObpydc.

$\left[\mathrm{Fe}\left(\mathrm{H}_{2} \mathrm{Bpz}\right)_{2}\right.$ (EtObpydc)] (3). The same method as for 1 was followed using EtObpydc (130 $\mathrm{mg}, 0.44 \mathrm{mmol})$, which yielded to an olive-green precipitate. Yield: $166 \mathrm{mg}(56 \%)$. Anal. Calcd for $3\left(\mathrm{C}_{28} \mathrm{H}_{32} \mathrm{~N}_{10} \mathrm{~B}_{2} \mathrm{O}_{4} \mathrm{Fe}\right)$ : $\mathrm{C}, 51.73 ; \mathrm{H}, 4.96 ; \mathrm{N}, 21.55$. Found: C, 50.99; H, 4.75; N, 21.83. MS (FTMS+pESI): m/z: $651.22\left[\mathrm{M}^{+}\right]$. Single crystals were obtained by slow diffusion in methanol/dichloromethane mixture under $\mathrm{Ar}$ using a single-tube glass vessel. The EtObpydc in $\mathrm{CH}_{2} \mathrm{Cl}_{2}$ was placed on the bottom of $\mathrm{Fe}\left(\mathrm{H}_{2} \mathrm{~B}(\mathrm{pz})_{2}\right)_{2}$-containing methanol solution, affording green needle crystals, namely 3, suitable for X-ray diffraction analysis, after overnight. Increasing crystallization time up to one week afforded prism shape crystals, which were identified as 3B.

[Fe( $\left(\mathrm{H}_{2} \mathrm{Bpz}_{2}\right)_{2}$ (i-PrObpydc)] (4). The same method as for 1 was followed using $i-$ PrObpydc (140 mg, $0.44 \mathrm{mmol}$ ), which yielded to an olive-green precipitate. Yield: $168 \mathrm{mg}(54 \%)$. Anal. Calcd. for $4\left(\mathrm{C}_{30} \mathrm{H}_{36} \mathrm{~N}_{10} \mathrm{~B}_{2} \mathrm{O}_{4} \mathrm{Fe}\right)$ : C, 53.13; $\mathrm{H}, 5.35 ; \mathrm{N}, 20.65$. 
Found: C, 51.96; H, 5.27; N, 20.48. MS (FTMS+pESI): m/z: $679.25\left[\mathrm{M}^{+}\right]$. The same crystallization method was followed as for 3 to afford single crystals of 4 using $i$ PrObpydc instead of EtObpydc. Increasing crystallization time up to one week afforded crystals of another morphology, namely 4B.

Characterization Techniques. Elemental analysis for $\mathrm{C}, \mathrm{H}$, and $\mathrm{N}$ were performed at Medac. NMR spectra were recorded at room temperature. with a Bruker Avance II $300 \mathrm{MHz}$ instrument. Chemical shifts $(\delta)$ are reported in ppm from $\mathrm{CDCl}_{3}(\delta=7.27$ $\mathrm{ppm})$ or DMSO- $d^{6}(\delta=2.50 \mathrm{ppm})$ for ${ }^{1} \mathrm{H}$ NMR. Mass spectra (MS) were recorded using $Q$-Exactive from ThermoFisher spectrometer. Infrared spectra were recorded on Shimadzu FTIR-8400S with KBr pellets. Diffuse reflectance spectra (DRS) were obtained with a PerkinElmer Lambda 9 UV/Vis/NIR spectrophotometer equipped with a $60 \mathrm{~mm}$ integrating sphere and converted into absorption spectra by using the Kubelka-Munk function, using $\mathrm{BaSO}_{4}$ as a reference. Thermogravimetric analyses (TGA) were performed in $\mathrm{N}_{2(\mathrm{~g})}\left(100 \mathrm{~mL} \mathrm{~min}^{-1}\right)$ at a heating rate of $10 \mathrm{Kmin}^{-1}$ from 298 to $873 \mathrm{~K}$ using a Mettler Toledo TGA/SDTA 851e analyser. Magnetic susceptibilities were measured on a Quantum design MPMS-5s SQUID magnetometer. The magnetic data were corrected for the sample holder and diamagnetic contributions. The crystal sample was quickly loaded into a gelatin capsule and immediately inserted within the SQUID cavity. ${ }^{57} \mathrm{Fe}$ Mössbauer spectra were recorded in transmission geometry with a constant acceleration mode conventional spectrometer equipped with a $50 \mathrm{mCi}{ }^{57} \mathrm{Co}(\mathrm{Rh})$ source and a Reuter Stokes proportional counter. The powdered samples were sealed in aluminum foil and spectra were recorded at 298 and $78 \mathrm{~K}$. All samples were grounded because spectra of fresh crystals systematically afforded line dissymmetry due to texture. The spectra were fitted using Recoil 1.05 Mössbauer Analysis software ${ }^{37}$. The isomer shift values are given with respect to $\alpha-\mathrm{Fe}$ at $298 \mathrm{~K}$.

Single Crystal X-ray Analyses. Suitable single crystals were selected for singlecrystal X-ray diffraction analysis. $20 \mathrm{~K}$ data for complexes 1 and 3 were collected with an Oxford Diffraction Xcalibur3 diffractometer, using monochromated Mo-Ka radiation $(\lambda=0.71073 \AA$ ). The diffractometer was fitted with a liquid helium lowtemperature device, Helijet Oxford Diffraction Cryostat. Crystallographic data at other temperatures were collected on a MAR345 image plate using MoKa radiation $(\lambda=$ $0.71073 \AA$ ). The crystals were selected, mounted in inert oil and transferred to the cold gas stream for flash cooling. Data were integrated by CrysalisAlisPro (Agilent Technologies (2014), Agilent Technologies UK Ltd., Oxford, UK, Xcalibur/SuperNova CCD system, CrysAlisPro Software system, Version 1.171.37.35 and 1.171.38.41). Absorption correction was applied using the integrated multi-scan absorption algorithm. The structures were solved by direct methods (SHELXS) and refined by full-matrix least-squares on $\mathrm{F}^{2}$ using SHELXL2014 ${ }^{38}$. The location of $\mathrm{Fe}$ atom was easily determined, and $\mathrm{O}, \mathrm{N}$, and $\mathrm{C}$ atoms were subsequently located in the difference Fourier maps. The non-hydrogen atoms were refined anisotropically. The $\mathrm{H}$ atoms were introduced in calculated positions and refined with fixed geometry with respect to their carrier atoms. DFIX, FLAT, DELU, SAME, ISOR and EADP constrains were applied in the refinement of the disordered boron-containing pyrazoyl group and alkyl ester substituents. CCDC 1829354 (1_95 K), 1832091 (2_20 K), 1829355 (3_296 K), 1829358 (3_92 K), 1832092 (3_20 K), 1829356 (4_297 K), 1829357 (4_90 K), 1832660 (3B_150 K), 1829660 (3B_100 K) and 1829661 (4B_175 K) are the supplementary crystallographic data for this paper. They can be obtained free of charge from the Cambridge Crystallographic Data Center via www.ccdc.cam.ac.uk/data request/cif. 


\section{ASSOCIATED CONTENT}

\section{Supporting Information}

The Supporting Information is available free of charge on the ACS Publications website at DOI: 10.1021/acs.inorgchem.xxxx

Overview of IR, structure and crystallographic data, Magnetic data for 4B, Mössbauer of 3B and 4B as well as computed frontier molecular orbitals for 1-4.

\section{AUTHOR INFORMATION}

\section{Corresponding Author}

*E-mail: yann.garcia@uclouvain.be.

\section{Notes}

The authors declare no competing financial interest.

\section{ACKNOWLEGDEMENT}

We acknowledge financial support from FNRS (PDR T.0102.15), Romanian National Authority for Scientific Research, CNCS-UEFISCDI, Project No. PN-II-RU-TE-20144-2695, FNRS-Academie Roumaine, WBI Roumanie, and COST Action Nos. CM1305 and CA15128. S. X. (24918505) and Y. GUO (28109061) are chargé de recherches from the FNRS. We thank Prof. J. Wouters for the courtesy use of a diffuse reflectance spectrometer.

\section{REFERENCES}

(1) (a) Gütlich, P.; Gaspar, A. B.; Garcia, Y. Spin state switching in iron coordination compounds. Beilstein J. Org. Chem. 2013, 9, 342-391;(b) Molnár G.; Rat, S.; Salmon, L.; Nicolazzi, W.; Bousseksou, A. Spin Crossover Nanomaterials: From Fundamental Concepts to Devices. Adv Mater. 2018, 30, 1703862.

(2) Zhao, T.; Boldog, I.; Spasojevic, V.; Rotaru, A.; Garcia, Y.; Janiak, C. Solvent-triggered relaxative spin state switching of $\left[\mathrm{Fe}\left(\mathrm{HB}(\mathrm{pz})_{3}\right)_{2}\right]$ in a closed nano-confinement of $\mathrm{NH}_{2}-\mathrm{MIL}-$ 101 (Al). J. Mater. Chem. C 2016, 4, 6588-6601.

(3) Murray, K. S.; Kepert, C. J. Cooperativity in spin crossover systems: memory, magnetism and microporosity. Top. Curr. Chem. 2004, 233, 195-228. 
(4) Brooker, S. Spin crossover with thermal hysteresis: practicalities and lessons learnt. Chem. Soc. Rev. 2015, 44, 2880-2892.

(5) Goodwin, H. A. Spin crossover in iron(II) tris(diimine) and bis(terimine) systems. Top. Curr. Chem. 2004, 233, 59-90.

(6) Onggo, D.; Goodwin, H. Steric Effects of the Spin State of Iron(II) in Complexes of Substituted Bipyridine Derivatives. Aust. J. Chem. 1991, 44, 1539-1551.

(7) Onggo, D.; Hook, J. M.; Rae, A. D.; Goodwin, H. A. The influence of steric effects in substituted 2,2' -bipyridine on the spin state of iron(II) in [FeN6] ${ }^{2+}$ systems. Inorg. Chim. Acta $1990,173,19-30$.

(8) James, B. R.; Parris, M.; Williams, R. J. P. Spectrophotometric and thermodynamic properties of some copper and iron complexes. J. Chem. Soc. 1961, 4630-4637.

(9) Büldt, L. A.; Prescimone, A.; Neuburger, M.; Wenger, O. S. Photoredox Properties of Homoleptic d6 Metal Complexes with the Electron-Rich 4,4' ,5,5' -Tetramethoxy-2,2' bipyridine Ligand. Eur. J. Inorg. Chem. 2015, 2015, 4666-4677.

(10) Real, J. A.; Muñoz, M. C.; Faus, J.; Solans, X. Spin Crossover in Novel Dihydrobis(1pyrazolyl)borate $\left[\mathrm{H}_{2} \mathrm{~B}(\mathrm{pz})_{2}\right]$-Containing Iron(II) Complexes. Synthesis, X-ray Structure, and Magnetic Properties of $\left[\mathrm{FeL}\left\{\mathrm{H}_{2} \mathrm{~B}(\mathrm{pz})_{2}\right\}_{2}\right] \quad(\mathrm{L}=1,10-$ Phenanthroline and 2,2'-Bipyridine). Inorg. Chem. 1997, 36, 3008-3013.

(11) Galet, A.; Gaspar, A. B.; Agusti, G.; Muñoz, M. C.; Levchenko, G.; Real, J. A. Pressure Effect Investigations on the Spin Crossover Systems $\left\{\mathrm{Fe}\left[\mathrm{H}_{2} \mathrm{~B}(\mathrm{pz})_{2}\right]_{2}(\mathrm{bipy})\right\}$ and $\left\{\mathrm{Fe}\left[\mathrm{H}_{2} \mathrm{~B}(\mathrm{pz})_{2}\right]_{2}\right.$ (phen)\}. Eur. J. Inorg. Chem. 2006, 2006, 3571-3573.

(12) Moliner, N.; Salmon, L.; Capes, L.; Muñoz, M. C.; Létard, J.-F.; Bousseksou, A.; Tuchagues, J.-P.; McGarvey, J. J.; Dennis, A. C.; Castro, M.; Burriel, R.; Real, J. A. Thermal and Optical Switching of Molecular Spin States in the $\left\{\left[\mathrm{FeL}\left[\mathrm{H}_{2} \mathrm{~B}(\mathrm{pz})_{2}\right]_{2}\right\}\right.$ Spin-Crossover System $(L=b p y$, phen). J. Phys. Chem. B 2002, 106, 4276-4283.

(13) (a) Milek, M.; Heinemann, F. W.; Khusniyarov, M. M. Spin Crossover Meets Diarylethenes: Efficient Photoswitching of Magnetic Properties in Solution at Room Temperature. Inorg. Chem. 2013, 52, 1 1585-1 1592; (b) Rösner, B.; Milek, M.; Witt, A.; Gobaut, B.; Torelli, P.; Fink, R. H.; Khusniyarov, M. M. Reversible Photoswitching of a Spin-Crossover Molecular Complex in the Solid State at Room Temperature. Angew. Chem., Int. Ed. 2015, 54, 12976-12980; (c) Moertel, M.; Witt, A.; Heinemann, F. W.; Bochmann, S.; Bachmann, J.; Khusniyarov, M. M. Synthesis, Characterization, and Properties of Iron(II) Spin-Crossover Molecular Photoswitches Functioning at Room Temperature. Inorg. Chem. 2017, 56, 13174-13186.

(14) Kulmaczewski, R.; Shepherd, H. J.; Cespedes, O.; Halcrow, M. A. A Homologous Series of $\left[\mathrm{Fe}\left(\mathrm{H}_{2} \mathrm{Bpz}_{2}\right)_{2}(\mathrm{~L})\right]$ Spin-Crossover Complexes with Annelated Bipyridyl Co-Ligands. Inorg. Chem. 2014, 53, 9809-9817.

(15) Luo, Y.-H.; Liu, Q.-L.; Yang, L.-J.; Sun, Y.; Wang, J.-W.; You, C.-Q.; Sun, B.-W. Magnetic observation of above room-temperature spin transition in vesicular nano-spheres. J. Mater. Chem. C 2016, 4, 8061-8069.

(16) Luo, Y.-H.; Nihei, M.; Wen, G.-J.; Sun, B.-W.; Oshio, H. Ambient-Temperature Spin-State Switching Achieved by Protonation of the Amino Group in [Fe( $\left(\mathrm{H}_{2} \mathrm{Bpz} 2\right)_{2}\left(\right.$ bipy- $\left.\left.\mathrm{NH}_{2}\right)\right]$. Inorg. Chem. 2016, 55, 8147-8152.

(17) Venema, F.; Nelissen, H. F. M.; Berthault, P.; Birlirakis, N.; Rowan, A. E.; Feiters, M. C.; Nolte, R. J. M. Synthesis, Conformation, and Binding Properties of Cyclodextrin Homo- and Heterodimers Connected through Their Secondary Sides. Chem. - Eur. J. 1998, 4, 2237-2250.

(18) Case, F. H. The Synthesis of Certain Substituted 2,2'-Bipyridyls. J. Am. Chem. Soc. 1946, 68, 2574-2577.

(19) Günyar, A.; Betz, D.; Drees, M.; Herdtweck, E.; Kühn, F. E. Highly soluble dichloro, dibromo and dimethyl dioxomolybdenum(VI)-bipyridine complexes as catalysts for the epoxidation of olefins. J. Mol. Catal. A: Chem. 2010, 331, 117-124.

(20) Delaive, P. J.; Lee, J. T.; AbruÑA, H.; Sprintschnik, H. W.; Meyer, T. J.; Whitten, D. G., LightInduced Electron Transfer Reactions of Hydrophobic Analogs of Ru(bipy) $3^{2+}$. In Inorganic and Organometallic Photochemistry, AMERICAN CHEMICAL SOCIETY: 1978; Vol. 168, pp 28-43.

(21) Marchivie, M.; Guionneau, P.; Létard, J. F.; Chasseau, D.; Howard, J. A. K. Thermal trapped iron(II) high spin state investigated by X-ray diffraction. J. Phys. Chem. Solids 2004, 65 , 17-23. 
(22) Konig, E.; Ritter, G.; Kulshreshtha, S. K. The nature of spin-state transitions in solid complexes of iron(II) and the interpretation of some associated phenomena. Chem. Rev. $1985,85,219-234$.

(23) Kumar, B.; Kumar, H.; Parmar, A. Iron(III) Perchlorate: A Reagent for Transesterification. Indian J. Chem., Sect. B: Org. Chem. Incl. Med. Chem. 1993, 32, 292-293.

(24) Ferrere, S.; Gregg, B. A. Photosensitization of $\mathrm{TiO}_{2}$ by [Fell (2,2'-bipyridine-4,4'-dicarboxylic acid $)_{2}(\mathrm{CN})_{2}$ ]: Band Selective Electron Injection from Ultra-Short-Lived Excited States. J. Am. Chem. Soc. 1998, 120, 843-844.

(25) Gütlich, P.; Garcia, Y.; Spiering, H., Spin transition phenomena. In Magnetism: Molecules to Materials IV: Nanosized Magnetic Materials, Joel S. Miller, M. D., Ed. Wiley-VCH Verlag GmbH \& Co. KGaA: 2003; pp 271-344.

(26) Slichter, C. P.; Drickamer, H. G. Pressure - Induced Electronic Changes in Compounds of Iron. J. Chem. Phys. 1972, 56, 2142-2160.

(27) Mishra, V.; Mukherjee, R.; Linares, J.; Codjovi, E.; Varret, F.; Lawson-Daku, M. Spin-transition in nearly cubic site in [Fe"l(L)3] [PF6]2. Hyperfine Interact. 2009, 188, 71-78.

(28) Gütlich, P.; Garcia, Y.; Goodwin, H. A. Spin crossover phenomena in Fe(II) complexes. Chem. Soc. Rev. 2000, 29, 419-427.

(29) Dîrtu, M. M.; Naik, A. D.; Rotaru, A.; Spinu, L.; Poelman, D.; Garcia, Y. Fell Spin Transition Materials Including an Amino-Ester 1,2,4-Triazole Derivative, Operating at, below, and above Room Temperature. Inorg. Chem. 2016, 55, 4278-4295.

(30) Gütlich, P.; Bill, E.; Trautwein, A. X., Mossbaver Spectroscopy and Transition Metal Chemistry. Fundamentals and Applications. Springer-Verlag Berlin Heidelberg: 2011.

(31) Neese, F. Software update: the ORCA program system, version 4.0. WIREs Comput. Mol. Sci. 2018, 8, e1327.

(32) Gu, Y.; Kar, T.; Scheiner, S. Fundamental Properties of the $\mathrm{CH} \cdots \mathrm{O}$ Interaction: Is It a True Hydrogen Bond? J. Am. Chem. Soc. 1999, 121, 9411-9422.

(33) Batsanov, S. S. Van der Waals Radii of Elements. Inorganic Materials 2001, 37, 871-885.

(34) (a) Grünert, G. C.; Reiman, S.; Spiering, H.; Kitchen, J. A.; Brooker, S.; Gütlich, P. Mixed Spin - State [HS - LS] Pairs in a Dinuclear Spin - Transition Complex: Confirmation by Variable Temperature ${ }^{57 F e}$ Mössbaver Spectroscopy. Angew. Chem., Int. Ed. 2008, 47, 2997-2999; (b) Griffin, M.; Shakespeare, S.; Shepherd, H. J.; Harding, C. J.; Letard, J.-F.; Desplanches, C.; Goeta, A. E.; Howard, J. A. K.; Powell, A. K.; Mereacre, V.; Garcia, Y.; Naik, A. D.; Mueller-Bunz, H.; Morgan, G. G. A Symmetry-Breaking Spin-State Transition in Iron(III). Angew. Chem., Int. Ed. 2011, 50, 896-900, S896/1-S896/17; (c) Lennartson, A.; Bond, A. D.; Piligkos, S.; McKenzie, C. J. Four - Site Cooperative Spin Crossover in a Mononuclear Fell Complex. Angew. Chem., Int. Ed. 2012, 51, 11049-1 1052.(d) Murnaghan, K. D.; Carbonera, C.; Toupet, L.; Griffin, M.; Dîrtu, M. M.; Desplanches, C.; Garcia, Y.; Collet, E.; Letard, J. -F.; Morgan, G. G. Spin-State Ordering on One Sub-lattice of a Mononuclear Iron(III) Spin Crossover Complex Exhibiting LIESST and TIESST. Chem. Eur. J. 2014, 20, 5613-5618. (e) Fitzpatrick, A. J.; Trzop, E.; Muller-Bunz, H.; Dîrtu, M. M.; Garcia, Y.; Collet, E.; Morgan, G. G. Electronic vs. structural ordering in a manganese(III) spin crossover complex. Chem. Commun. 2015, 51, 17540-17543.

(35) Garcia, Y.; Robert, F.; Naik, A. D.; Zhou, G.; Tinant, B.; Robeyns, K.; Michotte, S.; Piraux, L. Spin Transition Charted in a Fluorophore-Tagged Thermochromic Dinuclear Iron(II) Complex. J. Am. Chem. Soc. 2011, 133, 15850-15853.

(36) Zhuang, J. Z.; Tao, J.-Q.; Yu, Z.; Dun, C.-Y.; Liu, Y.-J.; You, X.-Z. A stacking spin-crossover iron(II) compound with a large hysteresis. J. Chem. Soc., Dalton Trans. 1998, 327-328.

(37) Lagarec, K.; Rancourt, D. G. Recoil, Mössbaver Spectral Analysis software for Windows 1.0, Department of Physics, University of Ottawa, 1998.

(38) Sheldrick, G. A short history of SHELX. Acta Crystallographica Section A 2008, 64, 112-122.

(39) Weigend, F. Accurate Coulomb-fitting basis sets for $\mathrm{H}$ to Rn. Phys. Chem. Chem. Phys. 2006, 8, 1057-1065.

(40) Pantazis, D. A.; Chen, X.-Y.; Landis, C. R.; Neese, F. All-Electron Scalar Relativistic Basis Sets for Third-Row Transition Metal Atoms. J. Chem. Theory Comput. 2008, 4, 908-919.

(41) Wüllen, C. v. Molecular density functional calculations in the regular relativistic approximation: Method, application to coinage metal diatomics, hydrides, fluorides and 
chlorides, and comparison with first-order relativistic calculations. J. Chem. Phys. 1998, 109, 392-399.

(42) (a) Grimme, S.; Ehrlich, S.; Goerigk, L. Effect of the damping function in dispersion corrected density functional theory. J. Comp. Chem. 2011, 32, 1456-1465; (b) Grimme, S.; Antony, J.; Ehrlich, S.; Krieg, H. A consistent and accurate ab initio parametrization of density functional dispersion correction (DFT-D) for the 94 elements H-PU. J. Chem. Phys. 2010, 132, 154104.

(43) Pinter, B.; Chankisjijev, A.; Geerlings, P.; Harvey Jeremy, N.; De Proft, F. Conceptual Insights into DFT Spin - State Energetics of Octahedral Transition - Metal Complexes through a Density Difference Analysis. Chem. - Eur. J. 2017, 24, 5281-5292. 
For Table of Contents Only

The combination between electronic substituent effect isopropyl acetate group and C$\mathrm{H}$... O interactions provides relatively high cooperativity, which leads to an abrupt SCO behavior in $\left[\mathrm{Fe}\left(\mathrm{H}_{2} \mathrm{Bpz}_{2}\right)_{2}(i\right.$-PrObpydc) $]$.

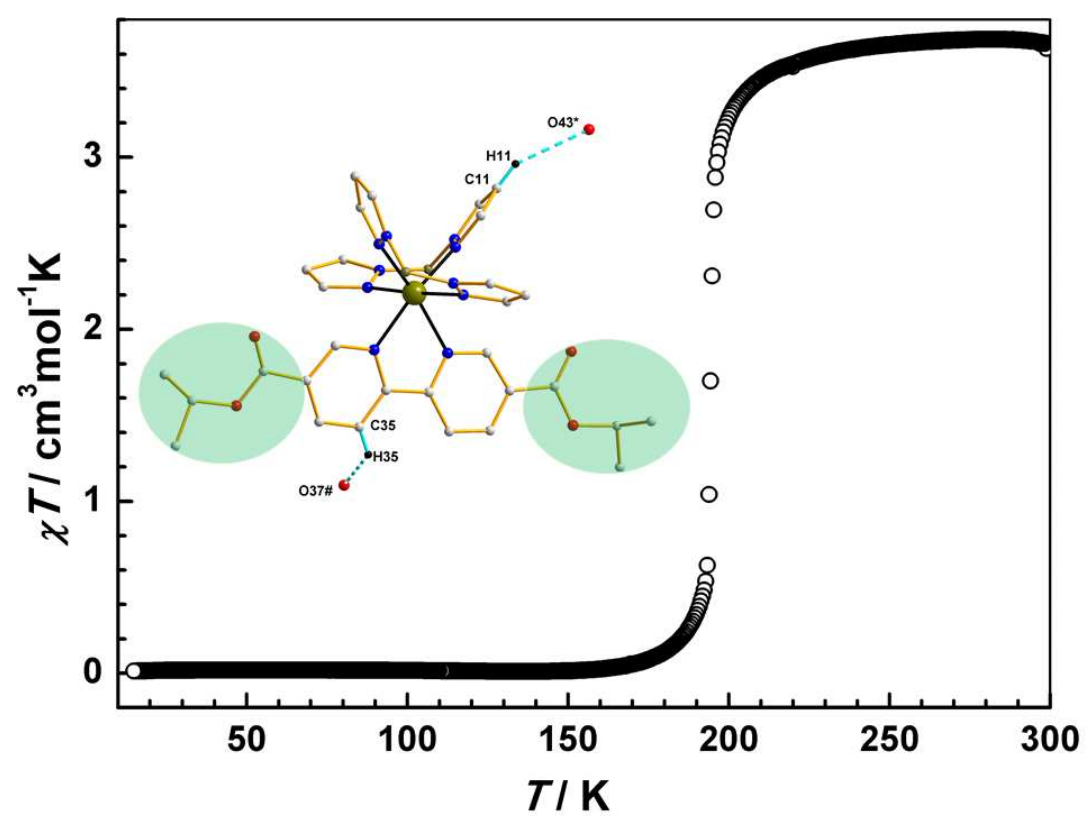

